\title{
GDNF rescues hyperglycemia-induced diabetic enteric neuropathy through activation of the PI3K/Akt pathway
}

\author{
Mallappa Anitha, ${ }^{1}$ Chetan Gondha, ${ }^{1}$ Roy Sutliff, ${ }^{2}$ Alexander Parsadanian, ${ }^{3}$ \\ Simon Mwangi, ${ }^{1}$ Shanthi V. Sitaraman, ${ }^{1}$ and Shanthi Srinivasan'
} 1Division of Digestive Diseases, Emory University, Atlanta, Georgia, USA. ${ }^{2}$ Division of Pulmonary, Allergy and Critical Care, Emory University and Veterans
Administration Medical Center, Atlanta, Georgia, USA. ${ }^{3}$ Department of Neurology, Washington University School of Medicine, St. Louis, Missouri, USA.

\begin{abstract}
Diabetes can result in loss of enteric neurons and subsequent gastrointestinal complications. The mechanism of enteric neuronal loss in diabetes is not known. We examined the effects of hyperglycemia on enteric neuronal survival and the effects of glial cell line-derived neurotrophic factor (GDNF) on modulating this survival. Exposure of primary enteric neurons to $20 \mathrm{mM}$ glucose (hyperglycemia) for 24 hours resulted in a significant increase in apoptosis compared with $5 \mathrm{mM}$ glucose (normoglycemia). Exposure to $20 \mathrm{mM}$ glucose resulted in decreased Akt phosphorylation and enhanced nuclear translocation of forkhead box O3a (FOXO3a). Treatment of enteric neurons with GDNF ameliorated these changes. In streptozotocin-induced diabetic mice, there was evidence of myenteric neuronal apoptosis and reduced Akt phosphorylation. Diabetic mice had loss of NADPH diaphorase-stained myenteric neurons, delayed gastric emptying, and increased intestinal transit time. The pathophysiological effects of hyperglycemia (apoptosis, reduced Akt phosphorylation, loss of inhibitory neurons, motility changes) were reversed in diabetic glial fibrillary acidic protein-GDNF (GFAP-GDNF) $\mathrm{Tg}$ mice. In conclusion, we demonstrate that hyperglycemia induces neuronal loss through a reduction in Aktmediated survival signaling and that these effects are reversed by GDNF. GDNF may be a potential therapeutic target for the gastrointestinal motility disorders related to diabetes.
\end{abstract}

\section{Introduction}

Diabetes mellitus is a common disorder and has a worldwide prevalence of $6-7 \%(1,2)$. Gastrointestinal dysfunction occurs in as many as $75 \%$ of diabetic patients $(3,4)$. Some of the common gastrointestinal problems seen in diabetes include delayed gastric emptying, diarrhea, constipation, and abdominal pain. The pathogenesis of intestinal motility dysfunction in diabetes remains unknown. The motility changes in the gastrointestinal tract in diabetes are considered to be an expression of autonomic neuropathy, with evidence for altered sympathetic function and cholinergic denervation of the gastrointestinal tract (5-7), vagal nerve dysfunction (8), sympathetic nerve damage (9), and damage to the enteric nerves (10-12).

The pathological lesions that occur in the enteric neurons in diabetes have been described. Loss of myenteric neurons has been reported in short-term diabetes $(13,14)$. A reduction in specific types of enteric neurons has been noted in several diabetic animal models, including streptozotocin-induced (STZ-induced) diabetic rats $(15,16)$, STZ-induced diabetic mice $(12)$, diabetic Chinese hamsters (6), and the OLETF rat model of type 2 diabetes (11). However, the mechanism underlying these changes in the enteric nervous system (ENS) in diabetes is not well defined. Neuronal

Nonstandard abbreviations used: CA-Akt, constitutively active Akt; ChAT, choline acetyltransferase; EFS, electric field-induced stimulation; ENS, enteric nervous system; FOXO, forkhead box O; GDNF, glial cell line-derived neurotrophic factor; GFAP, glial fibrillary acidic protein; NGF, nerve growth factor; nNOS, neuronal NO synthase; p, phospho; p-EGFP, plasmid-enhanced GFP; STZ, streptozotocin; Tg-C, GFAP-GDNF transgenic control; Tg-DM, GFAP-GDNF transgenic diabetic; WT-C, WT control; WT-DM, WT diabetic mice.

Conflict of interest: The authors have declared that no conflict of interest exists. Citation for this article: J. Clin. Invest. 116:344-356 (2006). doi:10.1172/JCI26295. apoptosis appears to contribute to the neurodegeneration seen in animal and cell culture models of diabetes (17). In the STZ model of diabetes, evidence of increased apoptosis in the dorsal root ganglion neurons, myenteric neurons, and nodose ganglia of diabetic rats has been demonstrated (18). Previous studies have shown that high glucose levels injure neuronal cell types, including Schwann cells, superior cervical ganglion neurons, and dorsal root ganglion neurons $(19,20)$. However, the effects of hyperglycemia on enteric neurons in culture have not been examined.

A reduction in neurotrophic factors can contribute to the changes noted in diabetic peripheral neuropathy $(21,22)$. Glial cell linederived neurotrophic factor (GDNF) is an important neurotrophic factor for the ENS $(23,24)$. GDNF acts with the coreceptor glial cell line-derived neurotrophic factor receptor $\alpha$ (GFR $\alpha 1)$ to activate the Ret tyrosine kinase receptor, stimulating both the MAPK and PI3K pathways (25). We and others have previously shown that the proliferation, maturation, migration, and survival of the enteric neurons are critically dependent on the activity of the Ret tyrosine kinase receptor that is expressed in the developing and mature enteric neurons $(23,25-27)$. GDNF-deficient mice also have severe intestinal aganglionosis (24). GDNF overexpression in glial fibrillary acidic protein-GDNF (GFAP-GDNF) Tg mice (Tg-DM mice) prevents a subpopulation of spinal and cranial motor neurons from developmental programmed cell death and promotes complete survival of injured neonatal neurons (28). One of the major intracellular signaling pathways for neurotrophic factors is the PI3K signaling pathway. GDNF activates the PI3K pathway to promote enteric neuronal survival (26). Decreased PI3K signaling has been implicated in vagal afferent neurons in STZ-induced diabetic rats (29). The effect of GDNF on diabetes-induced enteric neuronal damage is not known. 
A

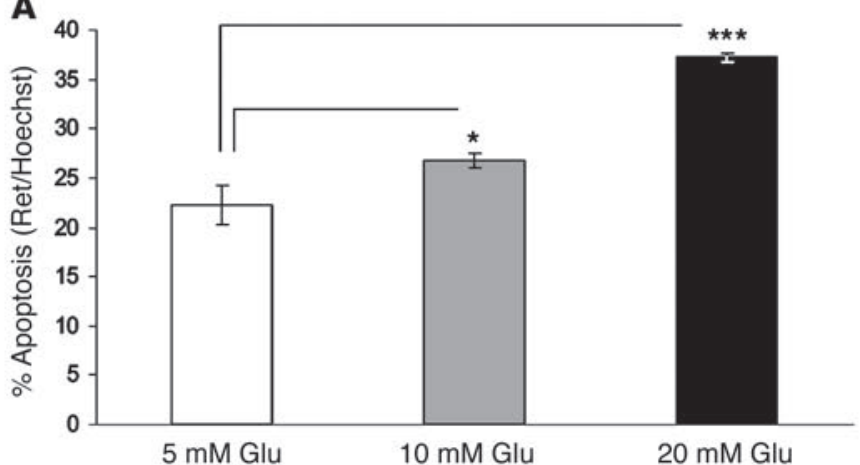

C

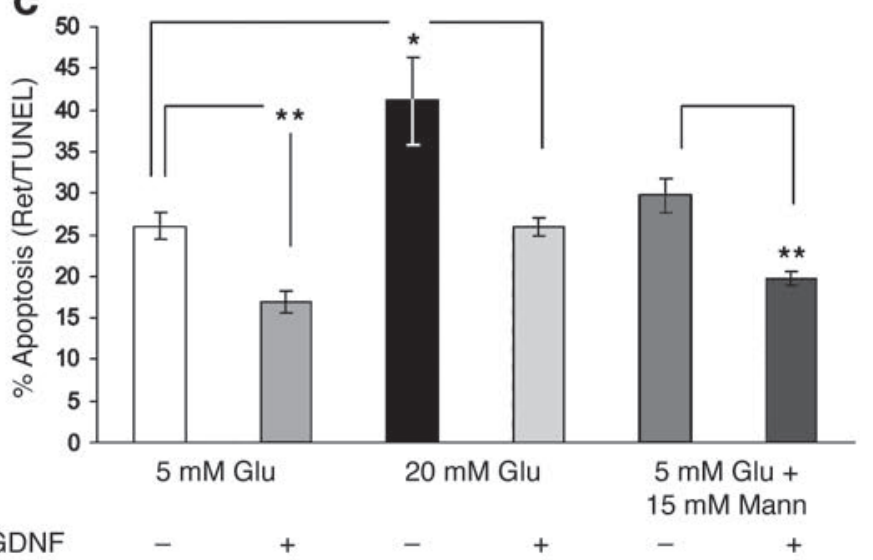

B

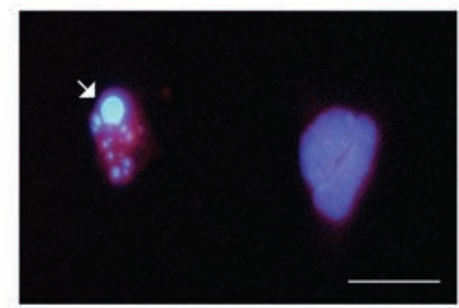

D
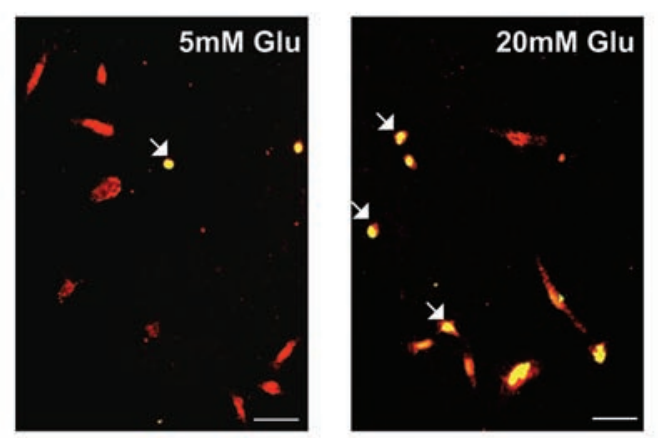

Figure 1

Hyperglycemia induces apoptosis in enteric neurons, and this is ameliorated by GDNF. To study the dose-dependent effects of hyperglycemia, different concentrations of glucose $(5,10$, or $20 \mathrm{mM}$ ) were used in serum-free/glucose-free media. (A) Apoptosis was assessed by the Ret/Hoechst staining method. (B) Magnified view of neurons to show the DNA fragmentation (arrow) seen during apoptosis compared with a healthy neuron (on the right). (C) Apoptosis was assessed using the Ret/TUNEL method in the presence or absence of GDNF and the stated glucose or mannitol concentrations. (D) Representative photomicrographs of enteric neurons cultured in the presence of $5 \mathrm{mM}$ and $20 \mathrm{mM}$ glucose and assessed for apoptosis using the Ret/TUNEL method. Ret (red) staining was used as a neuronal marker. Arrows identify the apoptotic cells (yellow) with condensed nuclei. Figure shows results of 4 independent experiments. ${ }^{*}<0.05 ;{ }^{* \star} P<0.01$; ${ }^{\star \star \star} P<0.001$. Scale bars: $20 \mu \mathrm{m}$ (B); $100 \mu \mathrm{m}$ (D). Glu, glucose.

In this study, we looked for evidence of damage to the enteric neurons in an experimental mouse model of diabetes as well as the effects of hyperglycemia on primary enteric neurons in culture and the possible mechanisms underlying this neuronal injury. The effects of the neurotrophic factor, GDNF, on hyperglycemiainduced toxicity was evaluated in vitro using primary enteric neurons in culture and in vivo using Tg mice overexpressing GDNF.

\section{Results}

Hyperglycemia-induced apoptosis in enteric neurons is inbibited by GDNF. We examined the effects of hyperglycemia on primary enteric neurons in culture. Enteric neurons from E14.5 rat guts were cultured for 24 hours in the presence of different concentrations of glucose $(5,10$, or $20 \mathrm{mM})$ in serum-free/glucose-free media. These concentrations of glucose have been shown to evoke a significant depolarization in isolated enteric neurons (30). Cultured cells were then fixed, and the effect of glucose on apoptosis of enteric neurons was assessed by the Ret/Hoechst staining method (26). Hyperglycemia caused a dose-dependent increase in enteric neuronal apoptosis (Figure 1A). Hoechst is a nuclear stain that detects DNA fragmentation and condensation in cells undergoing apoptosis (Figure 1B). Apoptosis was also assessed using the TUNEL method in conjunc- tion with staining for neurons with Ret. There was a significant increase in apoptosis at the $20 \mathrm{mM}$ glucose concentration compared with $5 \mathrm{mM}$ glucose (Figure 1C). We next determined whether the neurotrophic factor GDNF can ameliorate hyperglycemiainduced apoptosis. In the presence of GDNF, the glucose-induced apoptosis was significantly reduced (Figure 1C). To assess the role of increased osmolarity in the hyperglycemic culture medium, mannitol was used as an osmolar control. The increase in enteric neuronal apoptosis (assessed by Ret/TUNEL staining) was secondary to hyperglycemia, but not secondary to hyperosmolarity, as the addition of $15 \mathrm{mM}$ mannitol did not significantly increase apoptosis compared with $5 \mathrm{mM}$ glucose (Figure 1C). Representative photographs of enteric neurons cultured in the presence of $5 \mathrm{mM}$ and $20 \mathrm{mM}$ glucose and assessed for apoptosis using the TUNEL method are shown (Figure 1D).

Hyperglycemia is associated with decreased Akt phosphorylation. We next examined the role of the PI3K pathway in the glucose-induced modulation of enteric neuronal apoptosis. GDNF is a known activator of the PI3K pathway in enteric neurons. Activation of the $\mathrm{PI} 3 \mathrm{~K}$ pathway results in phosphorylation of Akt (26). Enteric neurons were cultured in medium containing 5 or $20 \mathrm{mM}$ glucose in the presence or absence of GDNF. Cells were fixed after culture for 


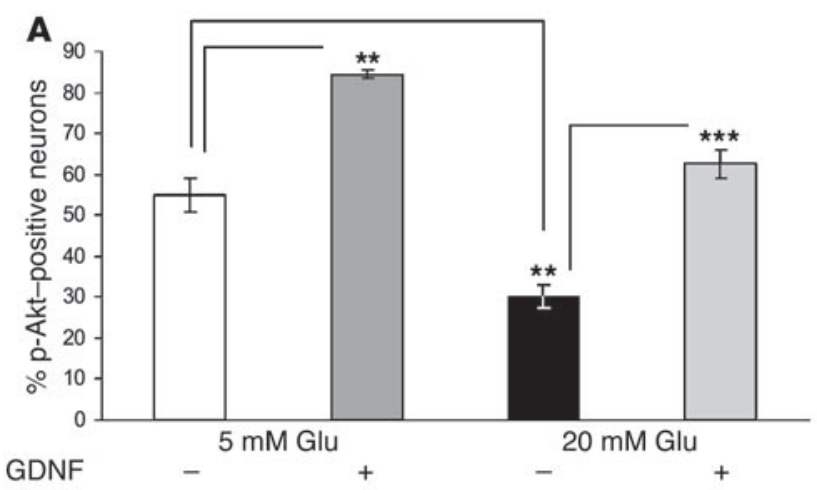

B

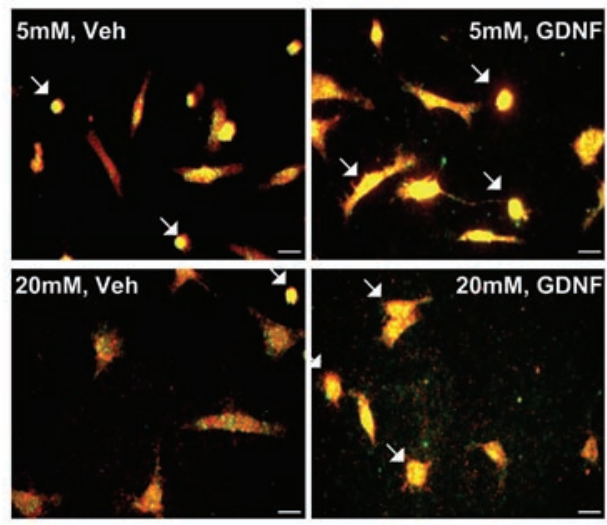

24 hours and stained using a primary antibody to phospho-Akt (p-Akt). Peripherin was used as a neuronal marker. The percentage of neurons staining positive for p-Akt was significantly reduced in the presence of $20 \mathrm{mM}$ glucose compared with $5 \mathrm{mM}$ glucose. The addition of GDNF significantly increased the p-Akt-stained neurons as shown in Figure 2, A and B.

Hyperglycemia is associated with increased $\mathrm{FOXO} 3$ a translocation. One of the main downstream targets of Akt is the forkhead family of transcription factors. Two members of the forkhead box O (FOXO) subfamily of forkhead transcription factors, FOXO1 and FOXO3a, critically regulate cellular differentiation (31) and neuronal survival (32). Enteric neurons were cultured in medium containing 5 or $20 \mathrm{mM}$ glucose in the presence or absence of GDNF. Cells were cultured for 24 hours, fixed, and stained with primary antibody to FOXO3a and peripherin. The percentage of neurons with nuclear translocation of forkhead was significantly higher in $20 \mathrm{mM}$ glucose compared with $5 \mathrm{mM}$ glucose. Addition of GDNF to the medium resulted in a significant reduction of forkhead nuclear translocation in the presence of $20 \mathrm{mM}$ glucose (Figure 3).

\section{Figure 3}

Hyperglycemia is associated with increased FOXO3a translocation. Enteric neurons were cultured in medium containing 5 or $20 \mathrm{mM}$ glucose in the presence or absence of GDNF. Cells were cultured for 24 hours, fixed, and stained for FOXO3a and the neuronal marker peripherin. (A) The percentage of neurons with nuclear translocation of FOXO3a under the different culture conditions is shown. (B) Representative photographs of $\mathrm{FOXO} 3 a /$ peripherin staining. Arrows represent neurons with nuclear translocation of $\mathrm{FOXO} a$. Results are from 4 independent experiments. ${ }^{*} P<0.05 ;{ }^{* \star *} P<0.001$. Scale bars: $20 \mu \mathrm{m}$.

\section{Figure 2}

Hyperglycemia is associated with decreased Akt phosphorylation. Enteric neurons were cultured in medium containing 5 or $20 \mathrm{mM}$ glucose in the presence or absence of GDNF. Cells were cultured for 24 hours, fixed, and stained using a primary antibody to $p$-Akt. Peripherin staining was performed as a counterstain to identify neurons. (A) Percentage of $\mathrm{p}$-Akt $\mathrm{A}^{+} /$peripherin ${ }^{+}$neurons under different culture conditions. Results are from 4 independent experiments. (B) Representative photographs of $\mathrm{p}$-Akt staining under different culture conditions. Arrows indicate p-Akt-stained neurons. ${ }^{* \star} P<0.01 ;{ }^{* *} P<0.001$. Scale bars: $20 \mu \mathrm{m}$.

Expression of constitutively active Akt rescues byperglycemia-induced ENS apoptosis. To confirm the role of Akt in rescuing hyperglycemia-induced apoptosis in enteric neurons, cells were transfected with a control plasmid-enhanced GFP (p-EGFP) vector or a constitutively active Akt (CA-Akt) construct (33) and cultured in the presence of $5 \mathrm{mM}$ or $20 \mathrm{mM}$ glucose for 24 hours. Apoptosis was evaluated using the Ret/TUNEL method. Overexpression of Akt but not p-EGFP was able to rescue the enteric neurons from undergoing apoptosis in the presence of $20 \mathrm{mM}$ glucose (Figure 4).

Diabetic mice exhibit enteric neuronal apoptosis and degeneration. In order to verify the changes induced by hyperglycemia on enteric neurons in culture and their reversal by GDNF in vivo, the STZinduced mouse model of diabetes was used. Diabetes was induced by intraperitoneal injection of STZ in WT (WT-DM) mice and in Tg-DM mice to assess the effects of overexpression of GDNF. Overexpression of GDNF in Tg-DM mice is driven by human GFAP promoter, which is known to be expressed in astrocytes in the central nervous system and some glial cells in the peripheral nervous system. WT control (WT-C) and GFAP-GDNF Tg control $(\mathrm{Tg}-\mathrm{C})$ mice were injected with vehicle.

WT-DM mice showed a significant decrease in body weight and a significant increase in the level of blood glucose when compared with WT-C mice 8 weeks after the induction of diabetes. The weight of Tg-C mice was lower than that of the WT-C mice. The $\mathrm{Tg}-\mathrm{DM}$ mice showed a significant increase in serum glucose level compared with WT-C and Tg-C mice (Table 1).
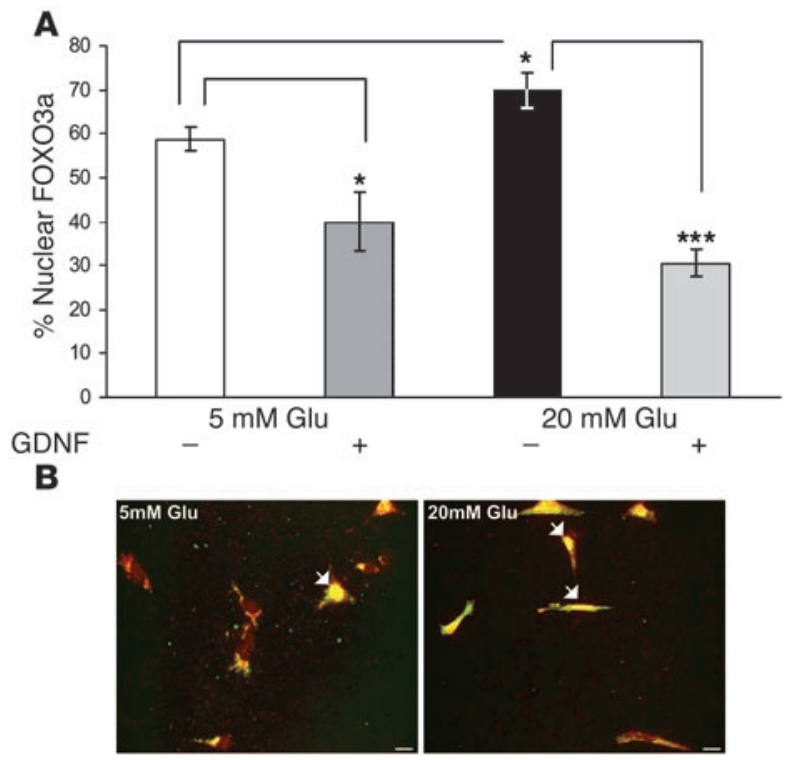


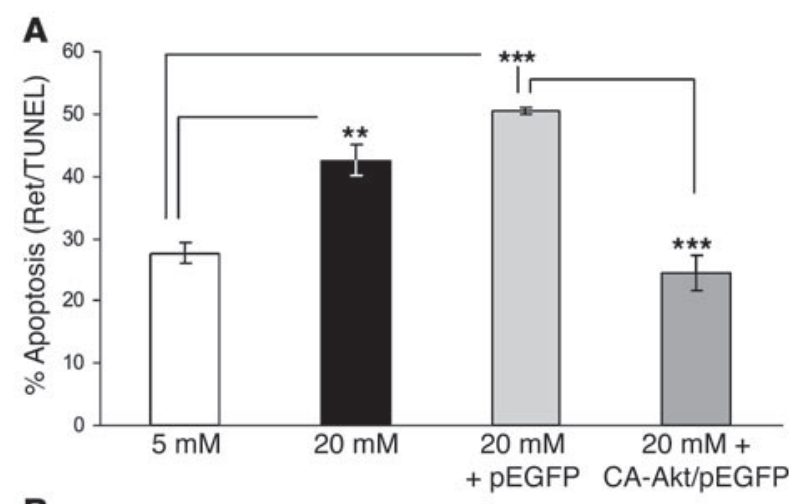

B

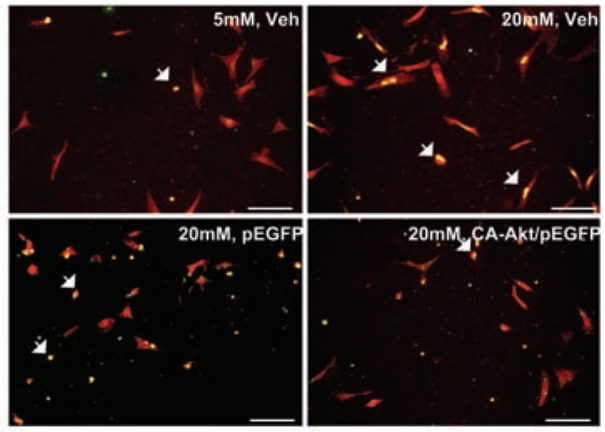

Electron microscopy provides the most convincing evidence of apoptotic cell death. A majority of the myenteric neurons from the proximal colon of diabetic mice showed evidence of neuronal apoptosis with clumping of the chromatin, condensation of the nucleus, mitochondrial ballooning, disruption of cristae, and disorganization of the neuropil. In contrast, neurons from the proximal colon of control mice displayed normal (diffuse) chromatin staining in the nucleus, normal mitochondria, and an organized neuropil (Figure 5).

GDNF overexpression prevents diabetic enteric neuronal apoptosis. The effect of GDNF on modulating the enteric neuronal apoptosis seen in diabetes was assessed in vivo using the Tg-DM mice. Apoptosis was assessed by activated caspase- 3 staining. Overexpression of GDNF in the ilea of Tg-DM mice was confirmed by RT-PCR (Figure 6A) and immunostaining using an antibody specific for GDNF (Figure 6B). GFAP was used as a glial marker. These photographs show that GDNF expression was directed to the glial cells in the enteric ganglia. Frozen cross sections of ilea from mice were assessed for myenteric neuronal apoptosis using double-labeling immunohistochemistry for cleaved caspase- 3 and peripherin. Eight weeks after the induction of diabetes, the WT-DM mice had a significantly higher number of apoptotic neurons in the myenteric ganglia compared with WT-C mice (Figure $6, C$ and D). The percentage change in myenteric ganglia containing cleaved caspase $-3^{+} /$peripherin ${ }^{+}$neurons compared with WT-C neurons is shown (Figure 6E). This increase in apoptosis is ameliorated in the Tg-DM mice.

Diabetes is associated with decreased expression of PI3K in enteric neurons. We next determined whether the increased

Table 1

\section{Figure 4}

Expression of CA-Akt rescues hyperglycemia-induced ENS apoptosis. Enteric neurons were transfected with control p-EGFP construct or a CA-Akt construct with p-EGFP, cultured in the presence of $5 \mathrm{mM}$ or $20 \mathrm{mM}$ glucose for 24 hours, and assessed for apoptosis using the Ret/TUNEL method. (A) Overexpression of Akt rescued the enteric neurons from undergoing apoptosis. (B) Representative photographs under different culture conditions. The red staining represents Ret, and apoptotic cells (arrows) are identified by the yellow condensed nuclei. Results are from 3 independent experiments. ${ }^{* \star} P<0.01$; ${ }^{\star \star \star} P<0.001$. Scale bars: $100 \mu \mathrm{m}$.

apoptosis seen in the condition of diabetes was associated with a decrease in PI3K signaling. Frozen cross sections of WT-C and WT-DM mice ilea were assessed for myenteric neuronal p-Akt expression. As shown in Figure 7, A-C, 8 weeks after the induction of diabetes, the WT-DM mice had significantly fewer p-Aktpositive neurons in the myenteric ganglia compared with WT-C mice. In addition, p-Akt was significantly reduced in myenteric neurons isolated from the ilea of diabetic mice compared with control mice as assessed by Western blot analysis using an antibody specific for p-Akt (Figure 7, D and E).

Diabetes is associated with loss of myenteric NADPH diaphorase-stained neurons, and this is rescued by GDNF. Having demonstrated that diabetes is associated with enhanced apoptosis in enteric neurons, we assessed the subtype of neurons affected in diabetes. Using wholemount analysis of mouse ilea, we assessed the neuronal NO synthase-containing (nNOS-containing) neurons (NADPH diaphorase stained), cholinergic neurons (choline acetyltransferase [ChAT] stained), and the total number of neurons (peripherin stained and PGP9.5 stained). The number of NADPH diaphorase-stained neurons, large and small fibers, was significantly decreased in WT-DM mice after 8 weeks of diabetes compared with WT-C mice (Figure 8, $\mathrm{A}-\mathrm{C})$. In the Tg-DM mice, the expression of GDNF ameliorated the loss of NADPH diaphorase-stained neurons, large and small fibers. No change in the number of acetylcholine esterase-stained excitatory neurons, large fibers or small fibers, was noted among all 4 groups of mice (Figure 8, D-F). This was confirmed by staining for cholinergic neurons using an antibody specific for ChAT (Figure 9, A and C). Total number of neurons was assessed by peripherin staining. The number of peripherin-positive neurons was significantly decreased in WT-DM mice compared with WT-C mice. In Tg-DM mice, the expression of GDNF ameliorated the loss of peripherinstained neurons (Figure 8, G and $\mathrm{H}$ ). Total number of neurons was also assessed by PGP9.5. The number of PGP9.5-positive neurons

Characteristics of control and STZ-induced diabetic mice

$\begin{array}{lcccc}\begin{array}{c}\text { Blood glucose } \\ \text { on the day of } \\ \text { injection } \mathbf{( m g / d l )}\end{array} & \begin{array}{c}\text { Blood glucose } \\ \text { 8 weeks after } \\ \text { injection } \mathbf{( m g / d l )}\end{array} & \begin{array}{c}\text { Weight on the } \\ \text { day of injection } \\ \mathbf{( g )}\end{array} & \begin{array}{c}\text { Weight } 8 \text { weeks } \\ \text { after injection } \\ \mathbf{( g )}\end{array} \\ \text { WT-C } & 158.5 \pm 10.5 & 141.8 \pm 0.8 & 41.25 \pm 0.5 & 46.3 \pm 2.1 \\ \text { WT-DM } & 152.6 \pm 6.2 & 465.5 \pm 8.5^{\mathrm{C}} & 43 \pm 1.5 & 34 \pm 2.3^{\mathrm{A}} \\ \text { Tg-C } & 145.5 \pm 23.5 & 149 \pm 0 & 32 \pm 1.5^{\mathrm{B}} & 35.3 \pm 1.8 \\ \text { Tg-DM } & 153.3 \pm 11 & 593 \pm 0^{\mathrm{D}} & 36.3 \pm 2 & 35.4 \pm 5.5\end{array}$

Body weight and blood glucose levels of WT-C, WT-DM, Tg-C, and Tg-DM mice are shown at baseline and 8 weeks after induction of diabetes. ${ }^{A} P<0.05$; ${ }^{B} P<0.01 ;{ }^{C} P<0.001$ compared with WT-C at corresponding time point. ${ }^{D} P<0.001$ compared with $\mathrm{Tg}-\mathrm{C}$ at corresponding time point. 


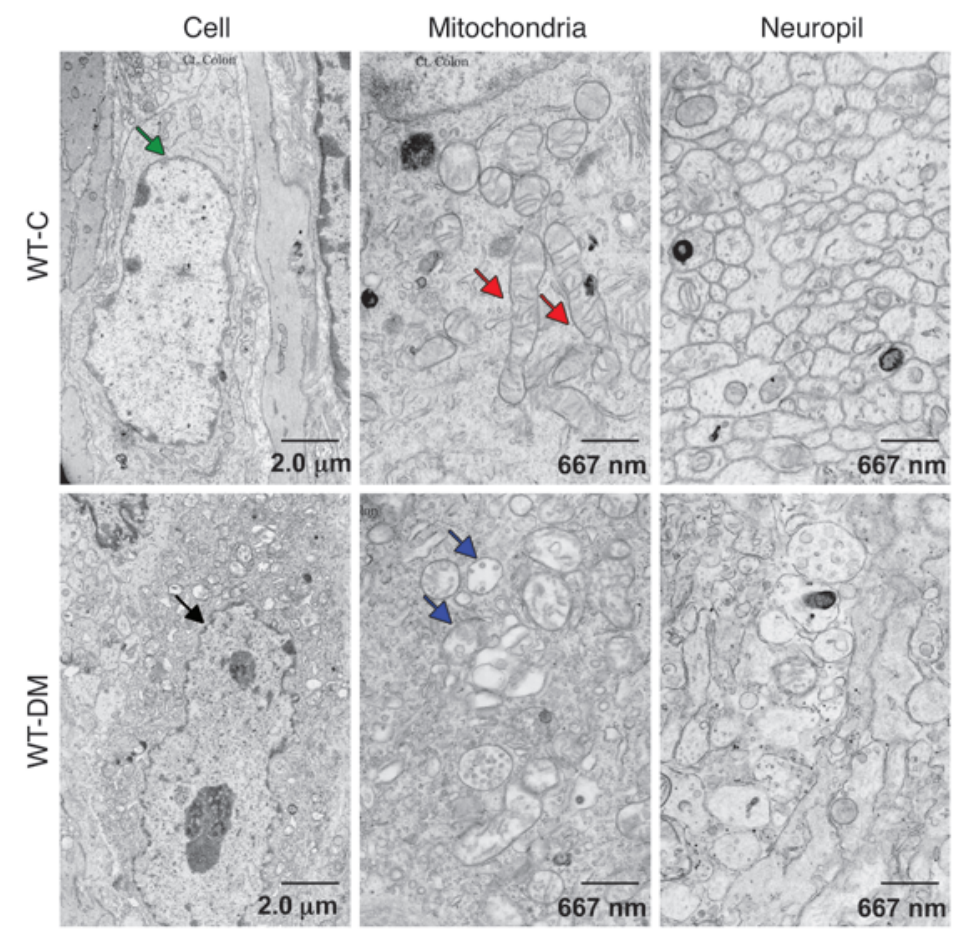

Figure 5

Diabetes is associated with electron microscopic evidence of myenteric neuronal apoptosis. Myenteric neurons from the proximal colons of diabetic mice showed evidence of neuronal apoptosis with clumping of the chromatin, condensation of the nucleus (black arrow), mitochondrial ballooning and disruption of cristae (blue arrows), and disorganization of the neuropil. In contrast, control neurons displayed normal diffuse chromatin staining in the nucleus (green arrow), normal mitochondria (red arrows), and an organized neuropil.

was significantly decreased in WT-DM mice compared with WT-C mice. In Tg-DM mice, the expression of GDNF ameliorated the loss of PGP9.5 (Figure 9, A and B).

Diabetic mice have delayed gastric emptying and increased intestinal transit, and these changes are reversed by GDNF. Gastric emptying and intestinal transit were assessed in WT-C, WT-DM, Tg-C, and Tg-DM mice as described in Methods. Figure 10A shows a representative photograph of the intestinal transit of methylene blue. As shown in Figure 10B, there was a significant delay in gastric emptying in WT-DM mice (8 weeks of diabetes) compared with WT-C mice. This delay in gastric emptying was significantly improved in $\mathrm{Tg}-\mathrm{DM}$ mice. The rate of intestinal transit 30 minutes after the administration of methylene blue was significantly higher in WT-DM compared with WT-C mice. The presence of the GFAP-GDNF transgene in the diabetic mice (Tg-DM) reduced the rate of intestinal transit (Figure 10C).

Diabetes is associated with impaired colonic relaxation in response to inhibitory neuronal stimulation, and these changes are reversed in the $\mathrm{Tg}-\mathrm{DM}$ mice. The effect of electric field-induced stimulation (EFS) of inhibitory neurons was assessed using isometric muscle tension recording. The effect of inhibitory neurons was confirmed by performing colonic longitudinal muscle strip stimulation in the presence of atropine and guanethidine. Percentage relaxation was calculated by determining the difference between the maximal baseline force and the minimum force following electrical stimulation and expressing this as a percentage of the force generated at baseline. Transmural EFS $(100 \mathrm{~V}, 20 \mathrm{~Hz}, 5$ milliseconds, 60 seconds), which evoked relaxation of the proximal colon, was significantly impaired in diabetic mice compared with controls. The induction of diabetes in the Tg-DM mice did not result in impairment of colonic relaxation (Figure 11A). Representative tracing of an EFS-induced relaxation recording is shown in Figure 11B. These data support amelioration of inhibitory neuronal loss in diabetes in the presence of GDNF overexpression. No change in the baseline amplitude of colonic contractions was noted between WT-C and WT-DM mice. Measurement of rebound contraction after relaxation with EFS was no different in all 4 mouse groups (data not shown), indicating no significant differences in the excitatory neuronal responses.

\section{Discussion}

The etiology of the gastrointestinal complications of diabetes is multifactorial. There is evidence of damage to the ENS in animal models of diabetes $(13,14)$ and in human diabetic patients (10). In the current study, we examined the role of hyperglycemia in inducing damage to the enteric neurons and the underlying mechanism of this damage. Using an in vitro culture system of enteric neurons as well as an in vivo STZ-induced diabetic model, we demonstrated that hyperglycemia is associated with enteric neuronal apoptosis. Further, we demonstrated alteration in the PI3K pathway and a subsequent loss of inhibitory myenteric neurons in neuronal cell culture as well as in diabetic mice. Importantly, we demonstrated, for what we believe is the first time, that the neurotrophic factor GDNF reverses hyperglycemia-induced neuronal apoptosis and loss of nNOS-containing neurons and also improves gastrointestinal motility in diabetic mice.

Neuronal apoptosis has been shown to contribute to the complications of diabetic retinopathy. Increased retinal neuronal apoptosis leading to neurodegeneration has been demonstrated in a STZ-induced rat model of diabetes (34). Diabetes-related programmed cell death has been demonstrated in the hippocampus of type 1 BioBreeding/Worcester (BB/W) rats (35). Apoptotic death in diabetic neuropathy has been related to hyperglycemia and oxidative stress $(20,36,37)$. In the human neuroblastoma cell line SH-SY5Y, exposure to $20 \mathrm{mM}$ glucose causes an increase in ROS, mitochondrial membrane depolarization, and cleavage of caspases (20). High glucose levels may result in depolarization of neurons and increased intracellular calcium (38). This may be a mechanism of glucotoxicity in enteric neurons, as they are known to be glucose responsive and to express an ATP-sensitive $\mathrm{K}^{+}$-channel (30).

Alterations in insulin signaling and tyrosine kinase activity as well as reduction in neurotrophic factor support have been implicated in the pathophysiology of diabetic complications. In our study, we have demonstrated that hyperglycemia decreased p-Akt both in cell culture and in a diabetic animal model. These changes were reversed by the neurotrophic factor GDNF. Impaired retrograde transport of neurotrophic factors has been demonstrated in somatic and autonomic nerves in experimental diabetes. In STZ-induced diabetic rats, a decrease in the activation of the PI3K pathway was associated with the impairment of retrograde nerve growth factor (NGF) transport in the vagus nerve (29). GDNF alleviated the glucoseinduced sensory deficits in a subset of sensory neurons called the IB-4-positive nonpeptidergic, unmyelinated primary afferent neurons (39). Recently, the role of insulin and its antiapoptotic effects 
A

A

B
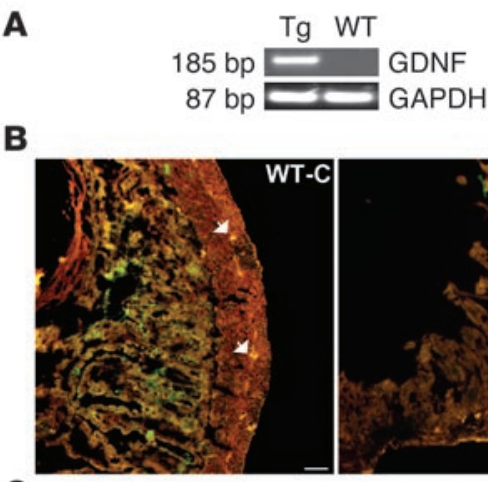

c

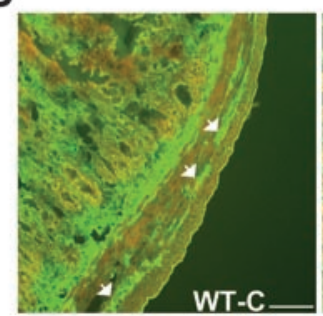

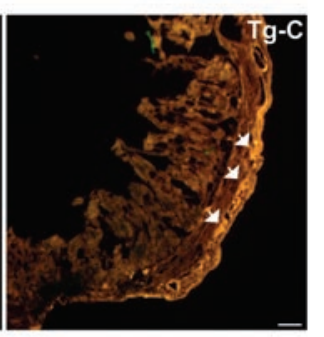

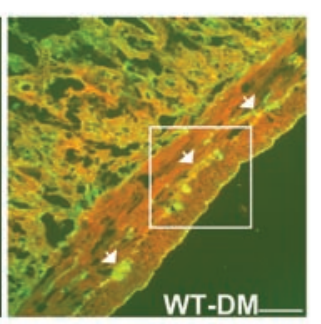

D
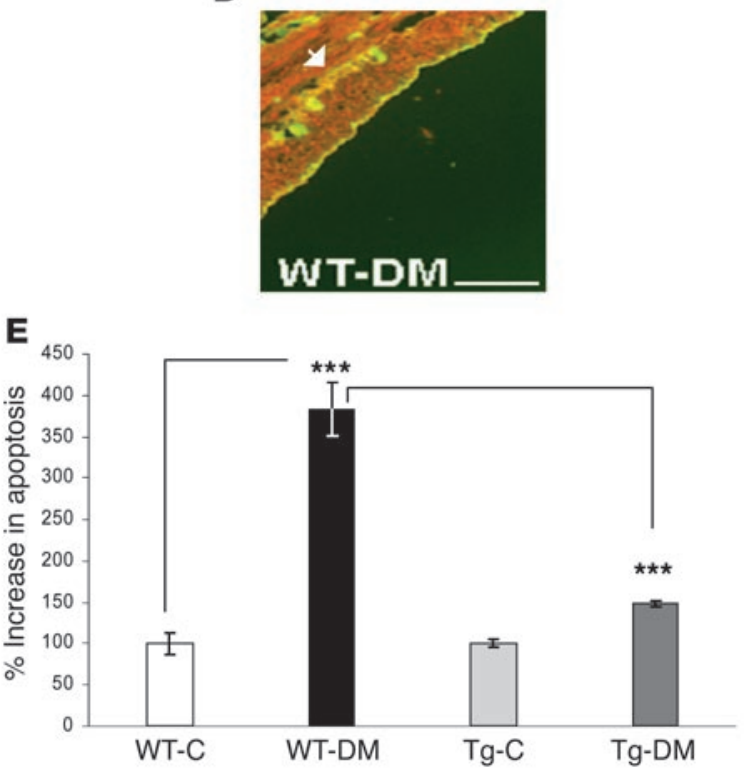

\section{Figure 6}

Diabetes is associated with increased cleaved caspase-3 staining in myenteric neurons. (A) Transgene GDNF is expressed in the ilea in Tg-DM mice. Analysis of Tg GDNF mRNA expression in the ilea of WT-C and Tg-C mice by RT-PCR, using primers that detect the mRNA transcribed from the Tg construct. (B) GDNF staining in WT and Tg mouse ilea sections. The arrows point to the myenteric ganglia. The yellow staining is due to colocalization of GDNF and GFAP. GFAP was used as a glial marker. A total of 3 experiments was performed. Scale bars: $100 \mu \mathrm{m}$. (C) Frozen cross sections of WT-C, WT-DM, Tg-C, and Tg-DM mouse ilea were assessed for myenteric neuronal apoptosis. Apoptosis was assessed using double-labeling immunohistochemistry for cleaved caspase-3 (red) and peripherin (green). Representative photographs for WT-C and WT-DM mice are shown. The arrows point to the myenteric ganglia. Apoptosis in the ganglia is identified by yellow staining due to colocalization of cleaved caspase-3 and peripherin. (D) Magnified view of white box in $\mathbf{C}$ shows the yellow-stained caspases positive enteric ganglia. (E) Percentage increase in cleaved caspase-3-positive enteric ganglia in different mice compared with WT-C. A total of 3 experiments was performed. ${ }^{* * *} P<0.001$. Scale bars: $100 \mu \mathrm{m}$.

in hippocampal neurons was shown in a type 1 diabetic model (40). The antiapoptotic effect of insulin is mediated through alteration of the PI3K pathway, leading to activation of NF-KB (41). Recently, the role of statins in the therapy of diabetic neuropathy involving the sciatic nerve was shown. Rouvastatin, an HMG CoA reductase inhibitor, has a favorable effect on diabetic neuropathy that is independent of its cholesterol-lowering effect. It restored nNOS expression in Schwann cells under high glucose conditions through activation of the PI3K pathway, resulting in restoration of the microcirculation of the sciatic nerve (42). IGF-1 activation of the PI3K pathway results in protection from glucose-mediated apoptosis in this model, and this protection is lost in the presence of the PI3K inhibitor LY294002 $(43,44)$. Growth factors such as NGF also block this induction of ROS and stabilize the mitochondrial membrane potential (20). Therapy with nerve growth factor improves unmyelinated fiber morphology and function in diabetic mice (45) and improves sensation and sensory function in patients with diabetic neuropathy (46). In a subpopulation of nonpeptidergic unmyelinated sensory neurons, GDNF but not NGF administration can selectively reverse deficits caused by diabetes (39). Our future studies will focus on the signal transduction differences between NGF and GDNF in ameliorating diabetic neuropathy. Our findings demonstrate a reduction in PI3K signaling in the enteric neurons in diabetes and the ability of GDNF overexpression to ameliorate these findings. Further studies will need to be done in both diabetic animal and human tissue samples to assess the levels of GDNF in enteric neurons.
Chronic hyperglycemia has been shown to impair PI3K signaling in skeletal muscle $(29,47)$. Amelioration of hyperglycemia without alteration of insulin levels normalizes the PI3K activity in skeletal muscle (29). Proper serum glucose control has been shown to prevent or ameliorate the nerve damage responsible for diabetic retinopathy and nephropathy $(48,49)$. In the current study, we report the effects of hyperglycemia on a primary embryonic enteric neuronal culture system. Hyperglycemia was shown to decrease PI3K signaling, although the exact mechanism is not known and needs to be further investigated. We also found a reduction in PI3K signaling in adult myenteric neurons. Our findings in the enteric neurons can be extended to adult neurons. We demonstrated the role of hyperglycemia-induced changes in the PI3K pathway and subsequent apoptosis and loss of enteric neurons. GDNF has also been shown to activate the MAPK pathway (25). We have previously reported that GDNF-mediated enteric neuronal survival is through the PI3K pathway and not the MAPK pathway (26). Further studies will need to be performed to evaluate the role of the MAPK pathway in hyperglycemia-induced enteric neuronal damage.

The molecular mechanism of hyperglycemia's alteration of PI3K activity is not known. Possible mechanisms include phosphoinositide-dependent protein kinase-1 (PDK-1) and PDK-2 inhibition, activation of PI3-phosphatase that leads to a decrease in the cellular contents of lipid products by PI3K, a defect in intracellular PI3K translocation, and activation of a phosphatase that may modify Akt/PKB activity (47). In cardiac myocytes, hyperglycemia results 

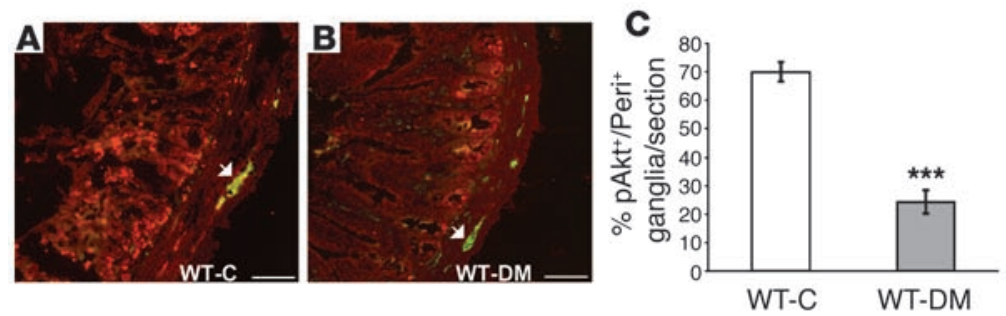
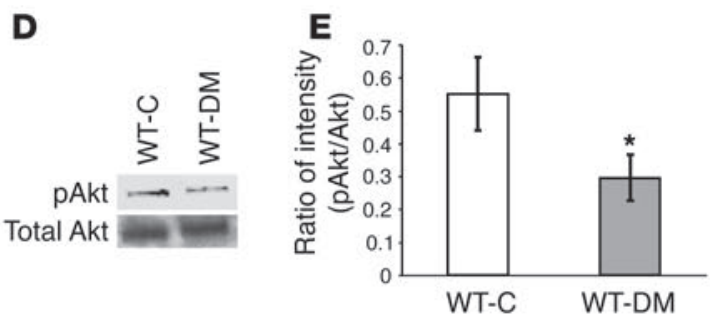

Figure 7

Diabetes is associated with decreased expression of PI3K in enteric neurons. Frozen cross sections of control (A) and STZ-induced diabetic mouse ilea (B) were assessed for myenteric neuronal p-Akt staining using an antibody specific for p-Akt (red). Arrows point to the myenteric ganglion stained with peripherin (green). The yellow staining represents $p$-Akt expression due to colocalization with peripherin. (C) The percentage of p-Akt-positive/peripherin-positive ganglia per section is shown. A total of 3 independent experiments was performed. (D) Representative Western blot of p-Akt and total Akt assessed in myenteric neurons isolated from the ilea of diabetic and control mice. (E) Ratio of $p$-Akt to Akt in myenteric neurons isolated from ilea of diabetic and control mice and assessed by Western blot analysis. A total of 3 independent experiments was performed. ${ }^{*} P<0.05 ;{ }^{* *} P<0.001$. Scale bars: $100 \mu \mathrm{m}$

in a reduction in the level of IGF-1 receptor (50). Similar mechanisms may be associated with the reduced PI3K signaling noted in our study. Another mechanism for reduced PI3K signaling in the diabetic animals may be secondary to the weight loss noted in these animals. Several factors contribute to the weight loss in diabetic animals, including glucosuria and diarrhea. In the diabetic Tg animals, the absence of weight loss may be due to the correction of the gastrointestinal motility disturbances that are noted in these animals.

We have demonstrated that overexpression of GDNF in glial cells adjacent to the enteric neurons results in an increase in NOcontaining inhibitory neurons. As previously shown, GDNF is efficiently secreted from astrocytes and acts in a paracrine fashion to promote complete and long-lasting survival of injured neonatal facial motor neurons (28). We believe that, similar to the effects of GDNF in the central nervous system, where the astrocytes secrete GDNF to affect motor neurons, the GDNF in the glial cells is secreted adjacent to enteric neurons. The NADPH diaphorasecontaining neurons could be inhibitory neurons, interneuronal neurons, or primary afferent neurons. Loss of nNOS-containing neurons in diabetes can result in delayed gastric emptying due to loss of neurons in the pylorus and accelerated intestinal transit due to loss of inhibition influence of these neurons in the small and large intestines. The defective gastric accommodation is due to impaired NOS expression in the gastric myenteric plexus in the spontaneously diabetic BB/W rat model (51). Delayed gastric emptying in diabetes is secondary to loss of neuronal NOS expression and function (12). Cellek et al. demonstrated loss of nitrergic function and neurons in the penises and pylori of STZ-treated diabetic rats, and only the loss of nNOS content and function was reversible by insulin, not the neuronal loss $(52,53)$. Our results show loss of nNOS-containing neurons in the intestine, which can contribute to the increased intestinal transit seen in diabetes. GDNF can prevent the enteric neuronal loss and ameliorate the increased intestinal transit in diabetes. Thus, the activation of the PI3K pathway can prevent the loss of nNOS-containing neurons seen in diabetes. We did not see a change in the cholinergic neurons in diabetes. This may reflect the duration of diabetes that we examined in our experiments.

Insulin improves the delayed gastric emptying seen in the STZ model of diabetes at 8 weeks (12). We now demonstrate that GDNF can perform a similar function by increasing the number of NADPH diaphorase-containing neurons. Other gastrointestinal problems in diabetes include diabetic diarrhea and constipation. The reduction in intestinal NADPH diaphorase-containing neurons and subsequent increase in intestinal transit can contribute to this diarrhea. NO-related mechanisms regulate human small intestinal motility (54). Symptoms of diabetic gastroparesis and diabetic diarrhea can worsen in patients with poor glucose control. Thus, both acute and chronic hyperglycemia can affect gastrointestinal motility, and we believe that alteration in the PI3K pathway can contribute to this. Loss of nNOS-containing enteric neurons has been noted in conditions of congenital pyloric stenosis, achalasia, and Hirschsprung disease (25). The regulation of the PI3K pathway may be altered in these conditions, and this area needs to be further investigated.

Our finding of reduced nitrergic neurons in diabetic neuropathy has potential therapeutic implications. Currently, the major drugs used for treating patients with diabetic gastropathy include domperidone (dopaminergic antagonist), metachlopramide (55), and erythromycin. Knowledge of the specific molecular mechanisms of hyperglycemia-induced enteric neuronal damage may have significant implications in the design and testing of therapeutic regimens for diabetic enteric neuropathy. Our results demonstrate the role of the PI3K pathway on hyperglycemia-induced neuronal loss. GDNF reverses the morphological and functional effects of hyperglycemia on enteric neuronal survival and may be a potential therapeutic target for gastrointestinal motility disorders in diabetes.

\section{Methods}

Materials. The components for primary culture were bovine insulin, bovine serum albumin fraction $V$, fetuin selenium, putrescine, and progesterone; all were obtained from Sigma-Aldrich. Also used were dispase and collagenase (CLS4; Worthington Biochemical Corp.), rat transferrin (ChromPure; Jackson ImmunoResearch Laboratories Inc.), 8-well culture slides and 6-well plates coated with poly-D-lysine and laminin (BD Biosciences), and prefilter and columns for magnetic separation (Miltenyi Biotec).

We also used the following: antibodies to low-affinity NGF receptor (p75NTR, clone192; Chemicon International, MAB365), c-Ret (ImmunoBiological Laboratories Inc.), peripherin for immunocytochemistry (Chemicon International, MAB1527), Akt (Cell Signaling Technology), peripherin for whole mount (Chemicon International, AB1530), p-Akt for Western blotting (Cell Signaling Technology), p-Akt for immunocytochemistry (Promega), rabbit IgG, HRP-linked (Cell Signaling Technology), FOXO3a (FKHRL1, Upstate USA Inc.), cleaved caspase-3 (Cell Signaling Technology), 
A WT-C

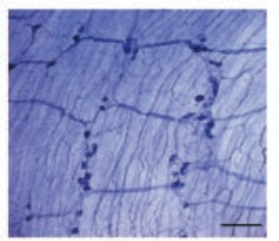

TR-C

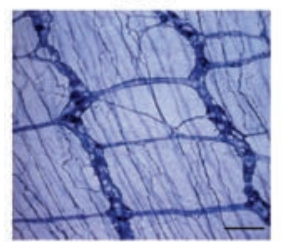

B
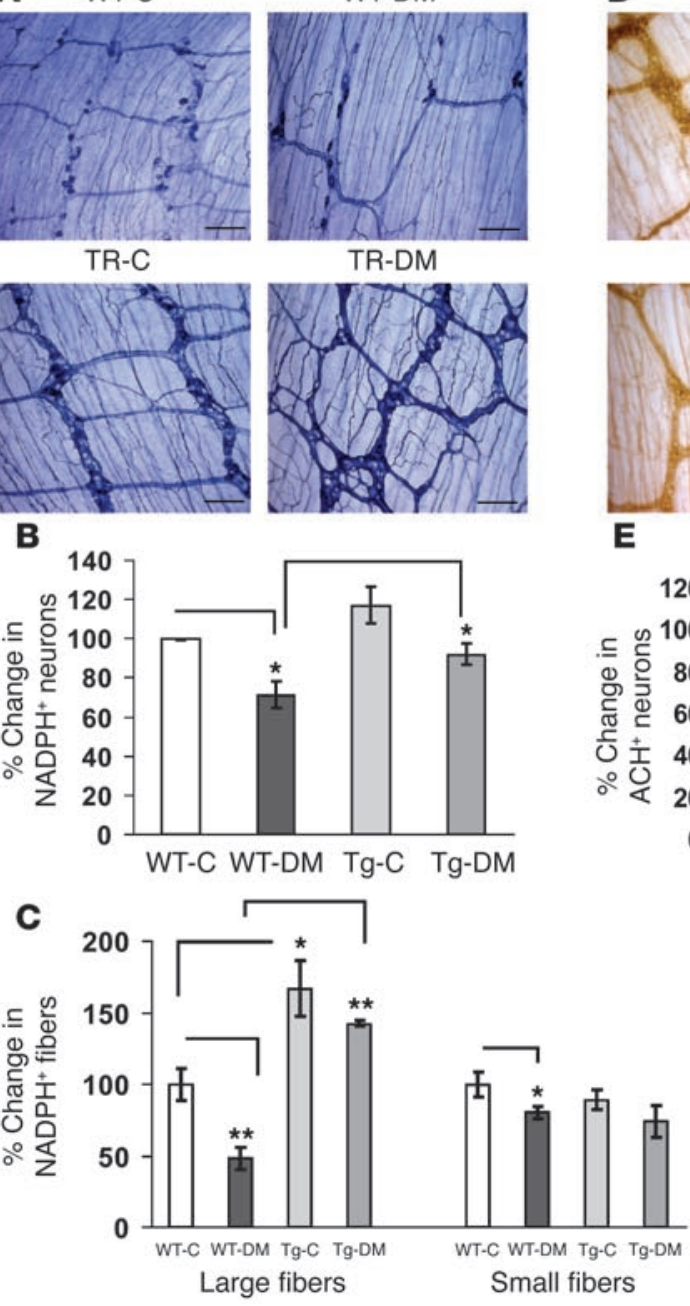

TR-DM

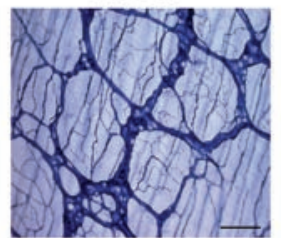

WT-C

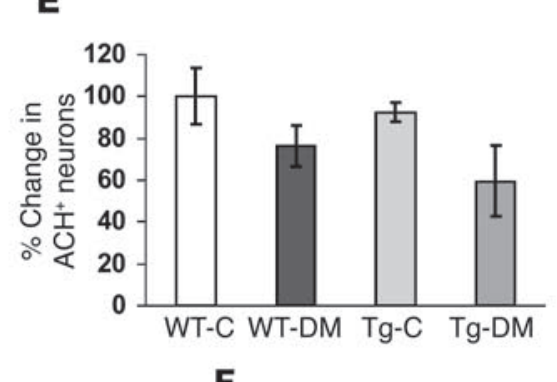

F

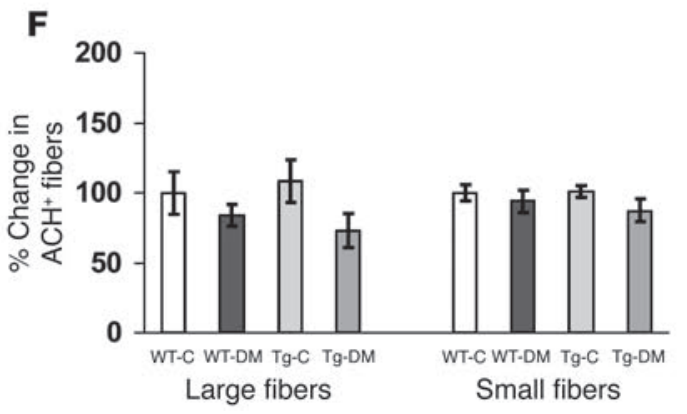

G

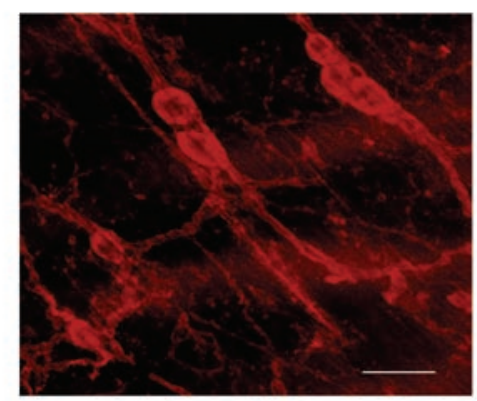

H

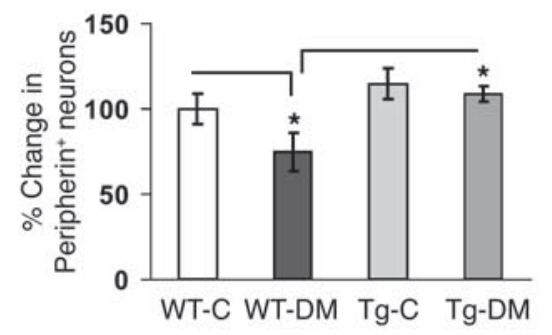

Figure 8

Diabetes is associated with loss of myenteric NADPH diaphorase-stained neurons, and this is rescued by GDNF. The myenteric plexuses and the longitudinal muscle layers from WT-C, WT-DM, Tg-C, and Tg-DM mice were separated from the rest of the intestines and used for staining. (A) Representative photographs of NADPH diaphorase-stained neurons. (B and C) Percentage change in the number of NADPH diaphorasestained neurons (B) and large and small fibers (C) relative to WT-C. (D) Representative photographs of acetylcholine esterase-stained neurons. ( $E$ and $\mathbf{F})$ Percentage change in the number of acetylcholine esterase-stained neurons (E) and large and small fibers (F) relative to WT-C. (G) Representative photograph of peripherin-stained neurons. (H) Percentage change in the number of peripherin-stained neurons relative to WT-C. As described in Methods, the number of neurons represents a sum of the neurons scored in 20 grids at $\times 40$ magnification. ${ }^{*} P<0.05$; ${ }^{* *} P<0.01$. Scale bars: $100 \mu \mathrm{M}(\mathbf{A}$ and $\mathbf{D}) ; 20 \mu \mathrm{m}(\mathbf{G})$.

GDNF and GFAP (Santa Cruz Biotechnology Inc.), goat anti-mouse, FITClabeled, donkey anti-rabbit biotin, donkey anti-mouse biotin, and peroxidase-conjugated streptavidin (Jackson ImmunoResearch Laboratories Inc.).

Other reagents were as follows: tyramide signal amplification kit (TSA-FITC or TSA-Cy3, NEN Life Science Products), Hoechst 33258 (Sigma-Aldrich), TUNEL Kit (Roche Diagnostics Corp.), STZ (SigmaAldrich), methylene blue (Mayne Pharma), dextrose (Sigma-Aldrich), mannitol (Fisher Diagnostics), PicoPure RNA Isolation Kit (Arcturus), Omniscript Reverse Transcription Kit (QIAGEN) and random hexamers (Invitrogen Corp.), Taq DNA polymerase (Promega), p-EGFP vector (BD Biosciences), CA-Akt construct (kind gift from Phil Stahl, Washington University, St. Louis, Missouri, USA), and lipofectamine 2000 (Invitrogen Corp.). GDNF was produced as previously described (56) and stored at $-70^{\circ} \mathrm{C}$ in aliquots. Fluorescent photomicrographs were obtained on a Leica microscope. Certain images were also taken using a Zeiss LSM 510 confocal microscope. Electron microscopic images were taken using a Hitachi H-7500 transmission electron microscope.

Primary culture and magnetic bead immunoselection of p75-expressing cells. Stomachs and small and large bowels from E14.5 Sprague-Dawley rat embryos (10-12 embryos) were dissociated with collagenase and dispase to prepare a single-cell suspension, as previously described $(23,57)$. In brief, the dissociated cells were incubated with a monoclonal antibody to low-affinity NGF receptor (p75NTR, $10 \mu \mathrm{g} / \mathrm{ml})$, washed, and labeled with goat anti-mouse IgG microbeads (50-nm diameter; Miltenyi Biotec). Cells expressing $\mathrm{p} 75$ bound to the microbeads were retained in the presence of a magnetic field ( 0.6 Tesla) while the remainder of the cells passed through. To collect the retained cells, the column was removed from the magnetic field, and the immunoselected cells were eluted from the column. The yield 

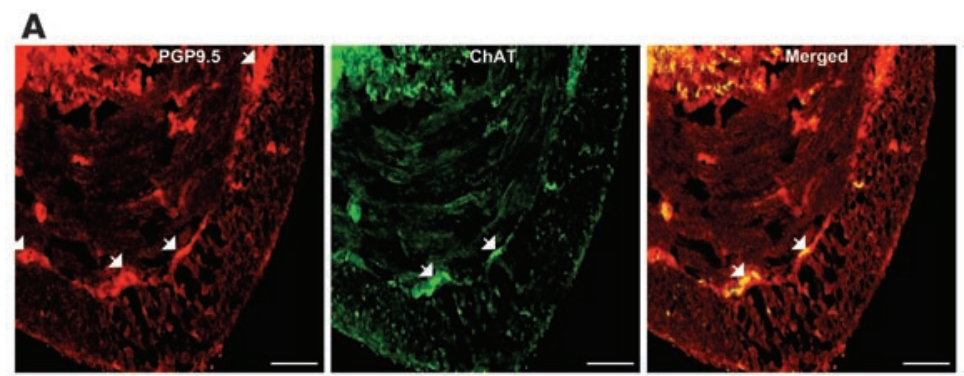

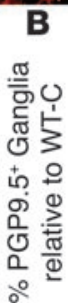

\section{0}

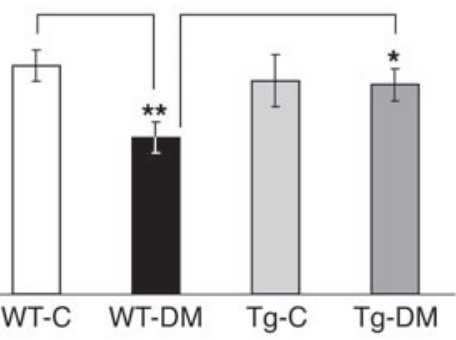

\section{c}

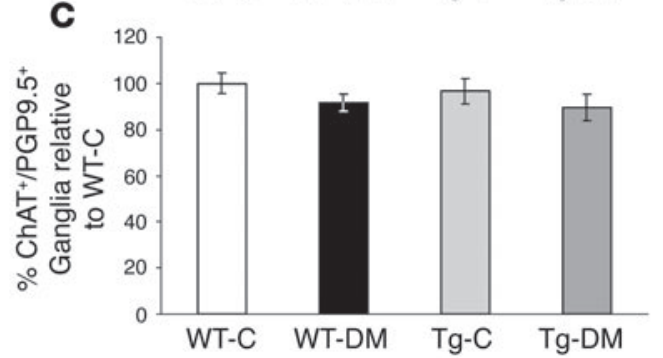

Figure 9

Assessment of PGP9.5 and ChAT-stained neurons in WT and Tg mice. (A) Representative photographs of cross sections of ilea from mice stained for PGP9.5 (red) and ChAT (green). (B and C) Percentage change in the number of ganglia staining positive for PGP9.5 (B) and ChAT/PGP9.5 (C) relative to WT-C is shown. A total of 3 independent experiments was performed. ${ }^{*} P<0.05$; ${ }^{* *} P<0.01$. Scale bars: $100 \mu \mathrm{M}$.

of immunoselected cells, calculated from several consecutive experiments, averaged $0.8-1.0 \times 10^{6}$ cells (approximately $10 \%$ of the total cells). Following immunoselection, cells were resuspended in modified N2 medium, and 12,500 trypan blue-excluding cells in $125 \mu \mathrm{l}$ of N2 medium were plated into a single well of an 8-well slide coated with poly-D-lysine and laminin. An additional $125 \mu \mathrm{l}$ of medium was added to each well with the desired factors. Cells were grown in the medium in a humidified tissue culture incubator containing $5 \% \mathrm{CO}_{2}$ at $37^{\circ} \mathrm{C}$. Unless otherwise stated, cells were grown in the presence of GDNF $(100 \mathrm{ng} / \mathrm{ml})$. As described by other investigators (58), our immunoselection method yielded a population of $80 \%$ Ret-positive cells after 24 hours of culture. The p75-negative fraction had less than 10\% Ret-positive cells.

Ret/Hoechst and Ret/TUNEL double labeling. Enteric neurons were treated with different glucose concentrations $(5,10$, or $20 \mathrm{mM}$ glucose or $5 \mathrm{mM}$ glucose plus $15 \mathrm{mM}$ mannitol $)$ in the presence or absence of GDNF $(100 \mathrm{ng} / \mathrm{ml})$ in serum-free/glucose-free medium and maintained in culture for 24 hours. Neurons were fixed with $4 \%$ paraformaldehyde ( $\mathrm{pH} 7.35,30$ minutes, $25^{\circ} \mathrm{C}$ ), and permeabilized with $0.1 \%$ Triton- $\mathrm{X} 100,0.1 \%$ sodium citrate in $\mathrm{PBS}(\mathrm{pH}$ 7.4; 2 minutes on ice). Staining for c-Ret was performed using a rabbit anti c-Ret primary antibody (1:100) in conjunction with a tyramide signal amplification kit (1:100, TSA-Cy3) as described previously (26). To visualize Hoechst-positive cells, slides were washed in PBS and then incubated with Hoechst stain $(2.5 \mu \mathrm{g} / \mathrm{ml})$ for 3 minutes at room temperature. At least
800 Ret-expressing neurons from 4 independent experiments were scored in a blinded fashion to determine the percentage of Hoechst $^{+} /$Ret $^{+}$cells. To visualize TUNEL-positive cells, slides were washed in PBS and then incubated with FITC-labeled dUTP in the presence of terminal deoxynucleotidyl transferase (TdT) for 1 hour at $37^{\circ} \mathrm{C}$. We scored 400 RET-expressing neurons in a blinded fashion to determine the percentage of TUNEL ${ }^{+} / \operatorname{Ret}^{+}$cells.

Analysis of Akt phosphorylation. p75 immunoselected enteric neurons were cultured in $\mathrm{N} 2$ medium containing 5 or $20 \mathrm{mM}$ glucose and in the presence or absence of GDNF $(100 \mathrm{ng} / \mathrm{ml})$ for 24 hours. Cultures were fixed in $4 \%$ paraformaldehyde $\left(30\right.$ minutes, $25^{\circ} \mathrm{C}$ ) and then permeabilized with $0.1 \%$ Triton-X 100 and $0.1 \%$ sodium citrate in PBS (2 minutes on ice). p-Akt-positive cells were visualized using an antibody specific for the phosphorylated form of Akt (p-Akt ${ }^{473}$; 1:100 dilution, $4^{\circ} \mathrm{C}$, overnight), followed by secondary antibodies and the TSA-Cy3 detection method as described above for Ret immunocytochemistry. Peripherin was used as a counterstain to identify neurons by using a TSA-FITC detection method. At least 800 peripherin-expressing neurons from 4 independent experiments were scored in a blinded fashion, and the percentage of p-Akt-positive cells was determined using Scion Image beta 4.0.2 software (Scion Corp.) to quantitate fluorescence.

Forkhead translocation. Immunoselected enteric neurons were cultured in $\mathrm{N} 2$ medium containing 5 or $20 \mathrm{mM}$ glucose and in the presence or absence of GDNF $(100 \mathrm{ng} / \mathrm{ml})$ for 24 hours. Cells were then fixed ( $4 \%$ paraformaldehyde, 30 minutes, $25^{\circ} \mathrm{C}$ ) and permeabilized with $0.1 \%$ Triton-X 100 and $0.1 \%$ sodium citrate in PBS ( 2 minutes on ice). Immunocytochemistry was first performed with a primary antibody to FOXO3a (1:100) and a TSA-Cy3 kit as described above. Cells were then stained with an anti-peripherin antibody and a TSA-FITC kit. At least 800 peripherin-expressing neurons from 4 independent experiments were scored in a blinded fashion, and the percentage of peripherin-expressing neurons with forkhead localized in the nucleus was determined using Scion Corp. imaging software to quantitate fluorescence.

CA-Akt transfection method. The role of Akt in rescuing the hyperglycemia-induced apoptosis in enteric neurons was confirmed by transfecting the cells with CA-Akt. CA-Akt lacks amino acid 4-129 and has a 14-amino acid src myristoylation signal on the amino terminus of Akt that targets Akt to the membrane (33). Enteric neurons were cultured in the presence of GDNF (100 ng/ml) for 24 hours. Medium was replaced with either 5 or $20 \mathrm{mM}$ glucose, and the cells were transfected with control p-EGFP construct ( $\mathrm{p}$-EGFP; $0.473 \mu \mathrm{g} / \mu \mathrm{l}$ ) or a CA-Akt construct (CA-Akt; $3.962 \mu \mathrm{g} / \mu \mathrm{l}$ ) with p-EGFP for 24 hours, using Lipofectamine 2000 per manufacturer's protocol. Cells were fixed and assessed for apoptosis by the Ret/TUNEL double-labeling method as described above.

STZ-induced diabetes mellitus in mouse model. All animal studies were approved by the Emory University Institutional Review Board. Tg-DM mice were generated by cloning the full-length mouse GDNF cDNA into the pGFAP-human growth hormone expression cassette containing a 2.2-kb fragment of the human GFAP promoter. Generation and characterization of these mice is described elsewhere (28). Integration of the transgene into the mouse genome was determined by PCR on genomic DNA extracted from mouse tail using forward (5'-AGCTCACTGCAGCCTCACCTACT- $3^{\prime}$ ) and reverse (5'-CAGGCATATTGGAGTCACTGG-3') primers in conditions described previously (28).

These mice overexpressed GDNF in both the central nervous system and the peripheral nervous system. The Tg-DM mice at birth exhibited an obvious tremor. The tremor gradually reduced with maturation and was undetectable after 2-3 weeks of age. The tremor may be a reflection of the transiently hyperinnervated neuromuscular junctions, and its disap- 
A

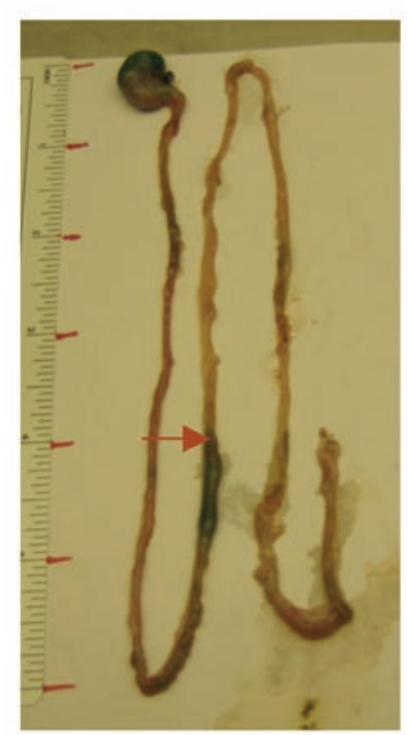

B
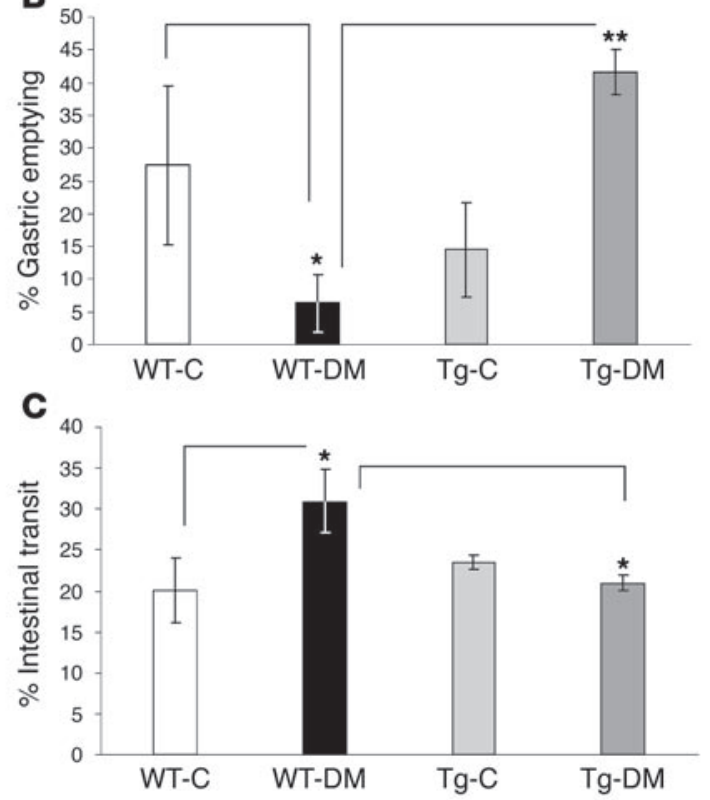

Figure 10

Assessment of gastric emptying and intestinal transit. (A) Photograph of stomach and intestine from WT-C mouse 30 minutes after administration of methylene blue dye. Red arrow shows the maximum transit of methylene blue. (B) Gastric emptying was assessed 30 minutes after administration of methylene blue in WT-C, WT-DM, Tg-C, and Tg-DM mice, as described in Methods. (C) Intestinal transit was assessed 30 minutes after administration of methylene blue and expressed as a percentage of the total intestinal length, as described in Methods. $n=4$ animals in each group. ${ }^{\star} P<0.05$; ${ }^{\star \star} P<0.01$.

pearance correlates with gradual loss of multiple innervation of skeletal muscles (28). These mice weighed $20 \%$ less than age-matched littermate controls. Despite this weight loss, eye opening, fur growth, weaning, and reproduction capacity were comparable to control. These mice were fed ad libitum. Eight-week-old male Tg-C and WT-C littermates were injected intraperitoneally with either STZ in $0.05 \mathrm{M}$ citrate buffer, $\mathrm{pH} 7.4(200 \mathrm{mg} / \mathrm{kg})$, or vehicle alone. Blood glucose and weight of the mice were measured prior to injection as well as 48 hours and 8 weeks after injection of STZ, and the averages are shown in Table 1 (48-hour measurement not shown).

Electron microscopy. Proximal colon tissue was obtained from WT-C and WT-DM mice and fixed with $2.5 \%$ glutaraldehyde in $0.1 \mathrm{M}$ cacodylate buffer, $\mathrm{pH} 7.2$, overnight at $4^{\circ} \mathrm{C}$, followed by 3 washes with the same buffer. Samples were then treated with $1 \%$ osmium tetroxide in $0.1 \mathrm{M}$ cacodylate buffer for 1 hour at room temperature. After fixation with osmium, samples were dehydrated through an ascending ethanol series and embedded with epoxy resin. Ultrathin sections were stained with uranyl acetate and lead citrate and examined with a Hitachi H-7500 transmission electron microscope.

RT-PCR. Total RNA was isolated from whole-ileum tissue of WT-C and Tg-DM mice using the PicoPure RNA Isolation Kit reagents (Arcturus), and $1 \mu \mathrm{g}$ RNA was reverse transcribed into first-strand cDNA using Omniscript reverse transcriptase (QIAGEN) and random hexamers (Invitrogen Corp.). Transgene mRNA was detected by RT-PCR using a set of primers that detect only the mRNA transcribed from the $\mathrm{Tg}$ construct $(28,59)$. As an internal control, we used primers specific to the GAPDH housekeeping gene. For semiquantitative PCR, $25 \mu$ r reactions were set up, comprising $\times 1$ Taq DNA polymerase buffer, $1.5 \mathrm{mM} \mathrm{MgCl}_{2}, 200 \mu \mathrm{M}$ dNTP mix, $0.4 \mu \mathrm{M}$ each of the GDNF or GAPDH oligonucleotide primers, $1.25 \mathrm{U}$ Taq DNA polymerase, and $1 \mu \mathrm{l}$ first-strand cDNA. The samples were heated for 3 minutes at $95^{\circ} \mathrm{C}$ and subjected to 30 cycles of PCR amplification, each cycle consisting of 30 seconds at $95^{\circ} \mathrm{C}$,
30 seconds at $60^{\circ} \mathrm{C}$, and 45 seconds at $72^{\circ} \mathrm{C}$. A final extension for 7 minutes at $72^{\circ} \mathrm{C}$ was performed before cooling to $4^{\circ} \mathrm{C}$. The reaction was analyzed on a $2 \%$ ethidium bromide-stained agarose gel, and the amplified products were visualized by UV transillumination.

Assessment of apoptosis and Akt phosphorylation in mouse ilea. Ilea immediately adjacent to the cecum were obtained from WT-C, WT-DM, $\mathrm{Tg}-\mathrm{C}$, and $\mathrm{Tg}-\mathrm{DM}$ mice and fresh frozen in OCT on dry ice. Frozen sections of $6 \mu$ m were obtained and fixed in $4 \%$ paraformaldehyde ( $\mathrm{pH} 7.35,30$ minutes, $25^{\circ} \mathrm{C}$ ), followed by permeabilization with $0.1 \%$ Triton-X 100 and $0.1 \%$ sodium citrate in PBS ( $\mathrm{pH} 7.4,2$ minutes on ice). Staining for cleaved caspase- 3 was performed using a rabbit anti-cleaved caspase-3 (Asp175) polyclonal antibody (1:100) in conjunction with a tyramide signal amplification kit (1:100, TSA-Cy3) as described previously (26). Sections were rinsed with PBS and blocked with 2\% BSA in PBS (1 hour, room temperature) and then double labeled for peripherin using a mouse anti-peripherin antibody $(1: 100)$ in conjunction with a goat anti-mouse FITC-linked antibody. Fifty peripherin-positive ganglia per section were scored in a blinded fashion to determine the percentage of caspase ${ }^{+} /$peripherin $^{+}$ganglia. At least 6 sections were scored for each condition in 3 separate mice.

For p-Akt/peripherin double labeling, a similar staining protocol was used, and the primary antibody rabbit anti-pS ${ }^{473}$ Akt antibody (1:100) was used. Fifty peripherin-positive ganglia per section were scored in a blinded fashion to determine the percentage of $\mathrm{p}-\mathrm{Akt}^{+} /$peripherin $^{+}$ganglia. At least 6 sections were scored for each condition in 3 separate mice.

GFAP/GDNF double labeling. GDNF overexpression in Tg mice was further confirmed by immunohistochemistry. Sections were fixed as described above and blocked with 5\% BSA (in PBS), and WT-C and Tg-C mouse sections were stained for GDNF using a rabbit anti-GDNF (1:50 in 1\% BSA) and TSA-Cy3 kit as described above. Sections were then counterstained with a goat anti-GFAP antibody (1:50) in conjunction with a donkey antigoat FITC lined antibody. GFAP was used as a glial cell marker. At least 5 sections were scored for WT-C and Tg-C mice.

Isolation (and protein extraction) of myenteric plexus from ilea of control and diabetic mice. WT-C and WT-DM mice ilea were collected in chilled L-15 medium and were cut into $1.0-1.5-\mathrm{cm}$ segments. Strips of longitudinal muscle with attached myenteric ganglia were dissected under a dissecting microscope and collected in L-15 medium on ice. The tissue was then transferred to a tube containing $2 \mathrm{ml}$ of collagenase, type II $(1 \mathrm{mg} / \mathrm{ml})$ in HBSS and incubated for 90 minutes. In step 1 , the tube was vortexed for 20 seconds. The partially digested tissue was allowed to settle and supernatant was collected and then screened under a dissecting microscope for myenteric ganglia or cells and spun down at $1,150 \mathrm{~g}$ for 10 minutes at $4^{\circ} \mathrm{C}$. In step 2, the cells were suspended in about $1 \mathrm{ml}$ of L-15 medium and kept on ice. Fresh collagenase solution $(1 \mathrm{ml})$ was added to the remaining partially digested pieces and incubated at $37^{\circ} \mathrm{C}$ for 30 minutes. This process was repeated 2-3 times. Steps 1 and 2 were repeated after every incubation, and cells were collected in the same tube. This process resulted in most of the myenteric plexus being removed from the smooth muscle and collected $(60,61)$. The cells 

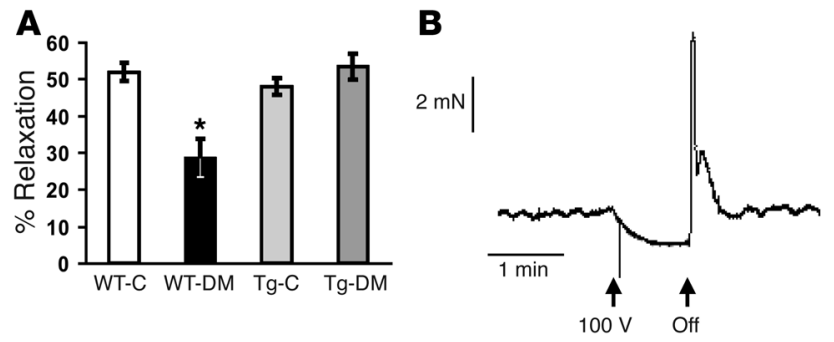

Figure 11

Diabetes is associated with impaired colonic relaxation in response to inhibitory neuronal stimulation, and these changes are reversed in Tg-DM mice. EFS-induced relaxation of longitudinal muscle strips was assessed as described in Methods. Percentage relaxation was calculated by determining the difference between the maximal force generated at baseline and the minimum force following electrical stimulation and expressing this as a percentage of the force generated at baseline. (A) Transmural EFS-induced relaxation $(100 \mathrm{~V}, 20 \mathrm{~Hz}$, 5 milliseconds, 60 seconds) of the proximal colon was assessed in WT-C, WT-DM, Tg-C, and Tg-DM mice. $n=3$ animals in each group. (B) Representative tracing of the recording of EFS-induced relaxation. The $y$ axis represents force in $\mathrm{mN}$, and the $x$ axis represents time. The arrows represent when the electrical stimulation was turned on and off. ${ }^{*} P<0.05$ versus all other groups.

were spun down, the supernatant removed completely, and the cells were washed in L-15 medium followed by ice-cold PBS. Lysis buffer (50-80 $\mu \mathrm{l}$ containing $1 \mathrm{mM}$ PMSF and $100 \mathrm{nM}$ okadaic acid) was added to the pellet, kept on ice for 5 minutes, sonicated 4 times for 5 seconds each on ice, and microcentrifuged for 10 minutes at maximum speed $(15,700 \mathrm{~g})$. Then the supernatant cell lysate was transferred to a new Eppendorf tube and stored at $-80^{\circ} \mathrm{C}$. Protein was measured by the Lowry method.

Western blotting. For each lane, $6 \mu \mathrm{g}$ of protein was loaded onto a $12 \%$ Tris- $\mathrm{HCl}$ gel. Western blotting for p-Akt was performed as described (62). A semiquantitative measurement of the band intensity was performed using the Scion imaging computer software program and expressed as pixel intensity per unit area.

Whole mount. Small bowel was dissected from mice, and the mesentery was removed. Three pieces of ileum ( $4 \mathrm{~cm}$; labeled 1, 2, and 3, 1 being the closest to the cecum) were cut along the mesentery and pinned down flat onto a glass dish with silicone coating. The intestines were fixed in $4 \%$ paraformaldehyde ( 1 hour, room temperature). The myenteric plexus and the longitudinal muscle layer were separated from the rest of the intestine and used for staining. Ileum piece 1 was used for peripherin staining, 2 for NADPH diaphorase, and 3 for acetylcholine esterase staining. For NADPH diaphorase staining, the fixed tissue was washed in PBS and incubated in diaphorase solution ( $\beta$-NADPH diaphorase, $1 \mathrm{mg} / \mathrm{ml}$; nitroblue tetrazolium, $0.1 \mathrm{mg} / \mathrm{ml}$; and $0.3 \%$ Triton-X 100 in PBS) for 1 hour at $37^{\circ} \mathrm{C}$. This was followed by washing in PBS and mounting of the tissue on a glass slide. For acetylcholine esterase staining, the fixed tissue was washed in PBS and incubated in fresh copper buffer solution ( $100 \mathrm{ml} \mathrm{dH_{2 }} \mathrm{O}, 7.2 \mathrm{mg}$ ethopropazine, $115.6 \mathrm{mg}$ acetylthiocholine iodide, $75.0 \mathrm{mg}$ glycine, $50.0 \mathrm{mg}$ copper sulfate pentahydrate, $885.0 \mathrm{mg}$ sodium acetate trihydrate; $\mathrm{pH}$ to 5.6 with glacial acetic acid) for 2 hours. This was followed by a wash in $\mathrm{dH}_{2} \mathrm{O}, 1$ minute in $1.25 \%$ sodium sulfide nonahydrate solution, a second wash in $\mathrm{dH}_{2} \mathrm{O}$, then mounting of the tissue on a glass slide. Peripherin staining was performed on the fixed intestinal tissue using a rabbit anti-peripherin polyclonal antibody (1:500) in conjunction with a tyramide signal amplification kit (1:100, TSA-Cy3) as described previously (63).
Myenteric fiber count was performed on both NADPH diaphorase and acetylcholine esterase-stained intestines by counting fibers crossing a $0.1 \mathrm{~mm}^{2}$ grid with 10 horizontal and 10 vertical lines. Twenty randomly selected fields per mouse were evaluated from 4 animals of each genotype. The neurons were counted within the $0.1 \mathrm{~mm}^{2}$ grid. Total number of neurons was expressed as peripherin-positive neurons per grid. Data were analyzed using the InStat software (version 2.04; GraphPad) in conjunction with ANOVA.

Immunohistochemistry for ChAT and PGP9.5. Frozen sections $(6 \mu \mathrm{m})$ were obtained from WT-C, WT-DM, Tg-C, and Tg-DM mice and fixed and permeabilized as described above. For PGP9.5 staining, the sections were blocked in $10 \%$ normal donkey serum and incubated with primary antibody (PGP9.5, 1:2000, in 1\% normal donkey serum) for 24 hours followed by detection with the TSA-Cy3 secondary detection system as described above. For ChAT staining, the sections were blocked with 5\% BSA and incubated overnight in 1:100 primary antibody in $1 \%$ BSA. Secondary detection was performed by incubation with an Alexa Fluor 488 rabbit anti-goat antibody (1:500) dilution. Three randomly selected fields per section were evaluated in a blinded fashion from at least 5 sections per mouse.

Measurement of intestinal transit and gastric emptying. WT-C, WT-DM, Tg-C, and $\mathrm{Tg}$-DM mice received an injection of $0.1 \mathrm{ml}$ of methylene blue-labeled $10 \%$ dextrose solution, using oral gavage. At the indicated time $(5$ or 30 minutes), mice were sacrificed. The stomach was clamped with a string above the lower esophageal sphincter and a string beneath the pylorus to prevent leakage of methylene blue. The intestinal transit was measured from the pylorus to the most distal point of migration of methylene blue. The total length of the small intestine was measured, and the transit time was expressed as percentage of total intestinal length as well as $\mathrm{cm}$ migration of methylene blue $(12,64)$. The stomach was cut just beneath the strings and frozen at $-70^{\circ} \mathrm{C}$ until measurement of gastric emptying. Gastric emptying of liquids was determined as described previously $(12,64)$. Excised stomachs were minced and homogenized for 30 seconds in $15 \mathrm{ml}$ of $0.1 \mathrm{~N}$ sodium hydroxide. An additional $5 \mathrm{ml}$ of $0.1 \mathrm{~N}$ sodium hydroxide was added and kept at room temperature for 1 hour. Supernatant $(5 \mathrm{ml})$ was then centrifuged at $1,250 \mathrm{~g}$ for 20 minutes at $4^{\circ} \mathrm{C}$. Absorbance of the samples was read at a wavelength of $570 \mathrm{~nm}$. The stomach and its contents obtained from mice sacrificed at the 5 -minute time point (after orogastric administration of methylene blue) served as a reference stomach measurement. The percentage of gastric emptying was calculated by the following formula: [(A570 reference - A570 sample)/A570 reference] $\times 100$. Gastric emptying of methylene blue was expressed as the percentage of gastric emptying of the sample compared with the reference stomach. Retro-orbital blood samples were obtained from mice before and 30 minutes after gavage with methylene blue and the serum assessed for methylene blue. No methylene blue was detected in the serum of mice fed with methylene blue. We also correlated the gastric emptying assessed by methylene blue with that of a colloidal suspension (charcoal) and found similar results.

Isometric muscle recording. Longitudinal muscle strips were obtained from the proximal colons of WT-C, WT-DM, Tg-C, and Tg-DM mice. The strips were mounted between 2 hooks and placed between 2 platinum electrodes in $50 \mathrm{ml}$ chambers containing Krebs buffer $(\mathrm{NaCl}, 118 \mathrm{mM}$; KCl, $4.7 \mathrm{mM}$; $\mathrm{KH}_{2} \mathrm{PO}_{4}, 1.2 \mathrm{mM} ; \mathrm{MgCl}_{2}, 1.2 \mathrm{mM}$; $\mathrm{NaHCO}_{3}, 23 \mathrm{mM}$; EDTA, $0.3 \mathrm{mM}$; glucose, $10 \mathrm{mM}$; and $\mathrm{CaCl}_{2}, 2.5 \mathrm{mM}$; $\mathrm{pH} 7.4$ ) at $37^{\circ} \mathrm{C}$ and continuously gassed with $95 \% \mathrm{O}_{2}$ and $5 \% \mathrm{CO}_{2}$. Tension was monitored with an isometric force transducer and recorded using the PowerLab recording software (version 5.2.1; ADInstruments). The intestinal strips were equilibrated for 1 hour with $4.9 \mathrm{mN}$ of tension applied. The colonic relaxation measured in response to transmural stimulation was recorded by EFS $(100 \mathrm{~V}, 20 \mathrm{~Hz}$, 5 millisecond pulse for a duration of 30 seconds) in the presence of atropine 
$(1 \mu \mathrm{M})$ and guanethidine $(1 \mu \mathrm{M})$. For quantitative determination of relaxation, we used intestinal strips from any given treatment condition and used the first relaxation under that condition. The NO dependence of the relaxation was confirmed by incubation with L-NAME prior to EFS. This relaxation was completely abolished by tetrodotoxin $\left(10^{-7} \mathrm{M}\right)$ which indicated mediation by a neuronal pathway. L-NAME $\left(10^{-4} \mathrm{M}\right)$ significantly reduced NANC by $70 \%$, suggesting that muscle relaxation was primarily mediated by NO production from the myenteric plexus.

Statistics. Results are expressed as mean \pm SEM. The data for all experiments was compared using a 2-tailed Student's $t$ test, assuming unequal variance. $P$ values of less than 0.05 were considered to be statistically significant.

\section{Acknowledgments}

This work is supported by NIH grants KO8 DK067045 (S. Srinivasan) and DK06411 (S.V. Sitaraman), a Crohn's and Colitis
Foundation of America senior research award (S.V. Sitaraman), a Digestive Diseases Research Center grant (DK064399), a Pilot and Feasibility Award from the Emory Center for Clinical and Molecular Nutrition (S. Srinivasan), and NIH grant NS42794 (A. Parsadanian). The authors thank Phil Stahl for providing us with the Akt constructs and Joshua Boutwell for his assistance with the isometric muscle recordings.

Received for publication July 15, 2005, and accepted in revised form November 22, 2005.

Address correspondence to: Shanthi Srinivasan, Division of Digestive Diseases, Emory University, Whitehead Research Building, Suite 246, 615 Michael Street, Atlanta, Georgia 30307, USA. Phone: (404) 727-5298; Fax: (404) 712-2980; E-mail: ssrini2@emory.edu.
1. Harris, M.I., et al. 1998. Prevalence of diabetes, impaired fasting glucose, and impaired glucose tolerance in U.S. adults. The Third National Health and Nutrition Examination Survey, 1988-1994. Diabetes Care. 21:518-524.

2. Mokdad, A.H., et al. 2001. The continuing increase of diabetes in the US [letter]. Diabetes Care. 24:412.

3. Goyal, R.K., and Spiro, H.M. 1971. Gastrointestinal manifestations of diabetes mellitus. Med. Clin. North Am. 55:1031-1044.

4. Verne, G., and Sninsky, CA. 1998. Diabetes and the gastrointestinal tract. Gastroenterol. Clin. North Am. 27:861-874.

5. Schmidt, R.E., Plurad, S.B., and Modert, C.W. 1983. Experimental diabetic autonomic neuropathy characterization in streptozotocin-diabetic SpragueDawley rats. Lab. Invest. 49:538-552.

6. Schmidt, R.E., et al. 1989. Ultrastructural and immunohistochemical characterization of autonomic neuropathy in genetically diabetic Chinese hamsters. Lab. Invest. 61:77-92.

7. Kniel, P., Junker, U., Perrin, I.V., Bestetti, G.E., and Rossi, G.L. 1996. Varied effects of experimental diabetes on the autonomic nervous system of the rat. Lab. Invest. 54:523-530.

8. Tougas, G., Hunt, R.H., Fitzpatrick, D., and Upton, A.R. 1992. Evidence of impaired afferent vagal function in patients with diabetes gastroparesis. Pacing Clin. Electrophysiol. 15:1597-1602.

9. Camilleri, M., and Malagelada, J.R. 1984. Abnormal intestinal motility in diabetics with the gastroparesis syndrome. Eur. J. Clin. Invest. 14:420-427.

10. He, C.L. 2001. Loss of interstitial cells of cajal and inhibitory innervation in insulin-dependent diabetes. Gastroenterology. 121:427-434.

11. Yoneda, S., Kadowaki, M., Kuramoto, H., Fukui, H., and Takaki, M. 2001. Enhanced colonic peristalsis by impairment of nitrergic enteric neurons in spontaneously diabetic rats. Auton. Neurosci. 92:65-71.

12. Watkins, C.C., et al. 2000. Insulin restores neuronal nitric oxide synthase expression and function that is lost in diabetic gastropathy. J. Clin. Invest. 106:373-384

13. Furlan, M.M., Molinari, S.L., and Miranda Neto, M.H. 2002. Morphoquantitative effects of acute diabetes on the myenteric neurons of the proximal colon of adult rats. Arq. Neuropsiquiatr. 60:576-581.

14. Fregonesi, C.E., Miranda-Neto, M.H., Molinari, S.L., and Zanoni, J.N. 2001. Quantitative study of the myenteric plexus of the stomach of rats with streptozotocin-induced diabetes. Arq. Neuropsiquiatr. 59:50-53.

15. Belai, A., Lincoln, J., Milner, P., and Burnstock, G. 1988. Progressive changes in adrenergic, serotonergic, and peptidergic nerves in proximal colon of streptozotocin-diabetic rats. Gastroenterology.
95:1234-1241.

16. Wrzos, H.F., Cruz, A., Polavarapu, R., Shearer, D., and Ouyang, A. 1997. Nitric oxide synthase (NOS) expression in the myenteric plexus of streptozotocin-diabetic rats. Dig. Dis. Sci. 42:2106-2110.

17. Russell, J.W., Sullivan, K.A., Windebank, A.J., Herrmann, D.N., and Feldman, E.L. 1999. Neurons undergo apoptosis in animal and cell culture models of diabetes. Neurobiol. Dis. 6:347-363.

18. Guo, C., Quobatari, A., Shangguan, Y., Hong, S., and Wiley, J.W. 2004. Diabetic autonomic neuropathy: evidence for apoptosis in situ in the rat. Neurogastroenterol. Motil. 16:335-345.

19. Russell, J.W., and Feldman, E.L. 1999. Insulin-like growth factor-I prevents apoptosis in sympathetic neurons exposed to high glucose. Horm. Metab. Res. 31:90-96.

20. Vincent, A.M., Brownlee, M., and Russell, J.W. 2002. Oxidative stress and programmed cell death in diabetic neuropathy. Ann. N. Y. Acad. Sci. 959:368-383.

21. Leinninger, G.M., Vincent, A.M., and Feldman, E.L. 2004. The role of growth factors in diabetic peripheral neuropathy. J. Peripher. Nerv. Syst. 9:26-53.

22. Schmidt, R.E. 2002. Neuropathology and pathogenesis of diabetic autonomic neuropathy. Int. Rev. Neurobiol. 50:257-292.

23. Heuckeroth, R.O., Lampe, P.A., Johnson, E.M., and Milbrandt, J. 1998. Neurturin and GDNF promote proliferation and survival of enteric neuron and glial progenitors in vitro. Dev. Biol. 200:116-129.

24. Sanchez, M.P., Silos-Santiago, I., Frisen, J., He, B., Lira, S.A., and Barbacid, M. 1996. Renal agenesis and the absence of enteric neurons in mice lacking GDNF. Nature. 382:70-73.

25. Takahashi, M. 2001. The GDNF/RET signaling pathway and human diseases. Cytokine Growth Factor Rev. 12:361-373.

26. Srinivasan, S., Anitha, M., Mwangi, S., and Heuckeroth, R.O. 2005. Enteric neuroblasts require the phosphatidylinositol 3-kinase/Akt/Forkhead pathway for GDNF-stimulated survival. Mol. Cell. Neurosci. 29:107-119.

27. Yan, H., et al. 2004. Neural cells in the esophagus respond to glial cell line-derived neurotrophic factor and neurturin, and are RET-dependent. Dev. Biol. 272:118-133.

28. Zhao, Z., et al. 2004. Overexpression of glial cell line-derived neurotrophic factor in the CNS rescues motoneurons from programmed cell death and promotes their long-term survival following axotomy. Exp. Neurol. 190:356-372.

29. Cai, F., and Helke, C.J. 2003. Abnormal PI3 kinase/ Akt signal pathway in vagal afferent neurons and vagus nerve of streptozotocin-diabetic rats. Brain Res. Mol. Brain Res. 110:234-244.

30. Liu, M., Seino, S., and Kirchgessner, A.L. 1999. Iden- tification and characterization of glucoresponsive neurons in the enteric nervous system. J. Neurosci. 19:10305-10317.

31. Accili, D., and Arden, K.C. 2004. FoxOs at the crossroads of cellular metabolism, differentiation, and transformation. Cell. 117:421-426.

32. Zheng, W.H., Kar, S., and Quirion, R. 2002. Insulin-like growth factor-1-induced phosphorylation of transcription factor FKHRL1 is mediated by phosphatidylinositol 3-kinase/Akt kinase and role of this pathway in insulin-like growth factor-1induced survival of cultured hippocampal neurons. Mol. Pharmacol. 62:225-233.

33. Kohn, A.D., Takeuchi, F., and Roth, R.A. 1996. Akt, a pleckstrin homology domain containing kinase, is activated primarily by phosphorylation. J. Biol. Chem. 271:21920-21926.

34. Barber, A.J., et al. 1998. Neural apoptosis in the retina during experimental and human diabetes. Early onset and effect of insulin. J. Clin. Invest. 102:783-791.

35. Li, Z.G., Zhang, W., Grunberger, G., and Sima, A.A. 2002. Hippocampal neuronal apoptosis in type 1 diabetes. Brain Res. 946:221-231.

36. Srinivasan, S., Stevens, M., and Wiley, J.W. 2000. Diabetic peripheral neuropathy: evidence for apoptosis and associated mitochondrial dysfunction. Diabetes. 49:1932-1938.

37. Schmeichel, A.M., Schmelzer, J.D., and Low, P.A. 2003. Oxidative injury and apoptosis of dorsal root ganglion neurons in chronic experimental diabetic neuropathy. Diabetes. 52:165-171.

38. Moriyama, R., et al. 2004. In vitro increase in intracellular calcium concentrations induced by low or high extracellular glucose levels in ependymocytes and serotonergic neurons of the rat lower brain stem. Endocrinology. 145:2507-2515.

39. Akkina, S.K., Patterson, C.L., and Wright, D.E. 2001. GDNF rescues nonpeptidergic unmyelinated primary afferents in streptozotocin-treated diabetic mice. Exp. Neurol. 167:173-182.

40. Li, Z.G., Zhang, W., and Sima, A.A. 2002. C-peptide prevents hippocampal apoptosis in type 1 diabetes. Int. J. Exp. Diabetes Res. 3:241-245.

41. Bertrand, F., et al. 1998. A role for nuclear factor kappaB in the antiapoptotic function of insulin. J. Biol. Chem. 273:2931-2938.

42. Ii, M., et al. 2005. Neuronal nitric oxide synthase mediates statin-induced restoration of vasa nervorum and reversal of diabetic neuropathy. Circulation. 112:93-102.

43. Delaney, C.L., Russell, J.W., Cheng, H.L., and Feldman, E.L. 2001. Insulin-like growth factor-I and over-expression of $\mathrm{Bcl}-\mathrm{xL}$ prevent glucose-mediated apoptosis in Schwann cells. J. Neuropathol. Exp. Neurol. 60:147-160.

44. Leinninger, G.M., Backus, C., Uhler, M.D., Lentz, 
S.I., and Feldman, E.L. 2004. Phosphatidylinositol 3-kinase and Akt effectors mediate insulin-like growth factor-I neuroprotection in dorsal root ganglia neurons. FASEB J. 18:1544-1546.

45. Elias, K.A., Cronin, M.J., Stewart, T.A., and Carlsen, R.C. 1998. Peripheral neuropathy in transgenic diabetic mice: restoration of C-fiber function with human recombinant nerve growth factor. Diabetes. 47:1637-1642.

46. Apfel, S.C., et al. 1998. Recombinant human nerve growth factor in the treatment of diabetic polyneuropathy. NGF Study Group. Neurology. 51:695-702.

47. Oku, A., et al. 2001. Inhibitory effect of hyperglycemia on insulin-induced Akt/protein kinase B activation in skeletal muscle. Am. J. Physiol. Endocrinol. Metab. 280:E816-E824.

48. [Anonymous]. 1993. The effect of intensive treatment of diabetes on the development and progression of long-term complications in insulin-dependent diabetes mellitus. The Diabetes Control and Complications Trial Research Group. N. Engl. J. Med. 329:977-986.

49. [Anonymous]. 2000. Retinopathy and nephropathy in patients with type 1 diabetes four years after a trial of intensive therapy. The Diabetes Control and Complications Trial/Epidemiology of Diabetes Interventions and Complications Research Group. N. Engl. J. Med. 342:381-389.

50. Ren, J., Duan, J., Hintz, K.K., and Ren, B.H. 2003. High glucose induces cardiac insulin-like growth factor I resistance in ventricular myocytes: role of Akt and ERK activation. Cardiovasc. Res. 57:738-748.

51. Takahashi, T., Nakamura, K., Itoh, H., Sima, A.A. and Owyang, C. 1997. Impaired expression of nitric oxide synthase in the gastric myenteric plexus of spontaneously diabetic rats. Gastroenterology. 113:1535-1544.

52. Cellek, S., Foxwell, N.A., and Moncada, S. 2003. Two phases of nitrergic neuropathy in streptozotocin-induced diabetic rats. Diabetes. 52:2353-2362.

53. Cellek, S., Qu, W., Schmidt, A.M., and Moncada, S. 2004. Synergistic action of advanced glycation end products and endogenous nitric oxide leads to neuronal apoptosis in vitro: a new insight into selective nitrergic neuropathy in diabetes. Diabetologia. 47:331-339.

54. Aros, S.D., and Camilleri, M. 2001. Small-bowel motility. Curr. Opin. Gastroenterol. 17:140-146.

55. Smith, D.S., and Ferris, C.D. 2003. Current concepts in diabetic gastroparesis. Drugs. 63:1339-1358.

56. Creedon, D.J., et al. 1997. Neurturin shares receptors and signal transduction pathways with glial cell line-derived neurotrophic factor in sympathetic neurons. Proc.Natl. Acad. Sci. U. S. A. 94:7018-7023.

57. Chalazonitis, A., et al. 1994. Neurotrophin-3 induces neural crest-derived cells from fetal rat gut to develop in vitro as neurons or glia. J. Neurosci. 14:6571-6584.

58. Chalazonitis, A., Rothman, T.P., Chen, J., and Gershon, M.D. 1998. Age-dependent differences in the effects of GDNF and NT-3 on the development of neurons and glia from neural crest-derived precursors immunoselected from the fetal rat gut: expression of GFR $\alpha-1$ in vitro and in vivo. Dev. Biol. 204:385-406.

59. Zhao, Z., et al. 2004. Overexpression of glial cell line-derived neurotrophic factor in the CNS rescues motoneurons from programmed cell death and promotes their long-term survival following axotomy. Exp. Neurol. 190:356-372.

60. Schafer, K.H., Saffrey, M.J., Burnstock, G., and Mestres-Ventura, P. 1997. A new method for the isolation of myenteric plexus from the newborn rat gastrointestinal tract. Brain Res. Brain Res. Protoc. 1:109-113.

61. Willard, A.L., and Nishi, R. 1985. Neurons dissociated from rat myenteric plexus retain differentiated properties when grown in cell culture. III. Synaptic interactions and modulatory effects of neurotransmitter candidates. Neuroscience. 16:213-221.

62. Srinivasan, S., Bernal-Mizrachi, E., Ohsugi, M., and Permutt, M.A. 2002. Glucose promotes pancreatic islet beta-cell survival through a PI 3-kinase/Aktsignaling pathway. Am. J. Physiol. Endocrinol. Metab. 283:E784-E793.

63. Heuckeroth, R.O., et al. 1999. Gene targeting reveals a critical role for neurturin in the development and maintenance of enteric, sensory, and parasympathetic neurons. Neuron. 22:253-263.

64. De Winter, B.Y., et al. 2002. Effect of inhibition of inducible nitric oxide synthase and guanylyl cyclase on endotoxin-induced delay in gastric emptying and intestinal transit in mice. Shock. 18:125-131. 